\title{
The link between outgoing longwave radiation and the altitude at which a spaceborne lidar beam is fully attenuated
}

\author{
Thibault Vaillant de Guélis ${ }^{1}$, Hélène Chepfer ${ }^{1},{\text { Vincent } \text { Noel }^{2}, \text { Rodrigo Guzman }^{3} \text {, Philippe Dubuisson }}^{4}$, \\ David M. Winker ${ }^{5}$, and Seiji Kato ${ }^{5}$ \\ ${ }^{1}$ LMD/IPSL, Université Pierre et Marie Curie, Paris, France \\ ${ }^{2}$ Laboratoire d'Aérologie, CNRS, Toulouse, France \\ ${ }^{3}$ LMD/IPSL, CNRS, École polytechnique, Palaiseau, France \\ ${ }^{4}$ Laboratoire d'Optique Atmosphérique, Université Lille, Lille, France \\ ${ }^{5}$ NASA Langley Research Center, Hampton, Virginia, USA \\ Correspondence to: Thibault Vaillant de Guélis (thibault.vaillant-de-guelis@1md.polytechnique.fr)
}

Received: 13 April 2017 - Discussion started: 6 June 2017

Revised: 20 September 2017 - Accepted: 20 October 2017 - Published: 4 December 2017

\begin{abstract}
According to climate model simulations, the changing altitude of middle and high clouds is the dominant contributor to the positive global mean longwave cloud feedback. Nevertheless, the mechanisms of this longwave cloud altitude feedback and its magnitude have not yet been verified by observations. Accurate, stable, and long-term observations of a metric-characterizing cloud vertical distribution that are related to the longwave cloud radiative effect are needed to achieve a better understanding of the mechanism of longwave cloud altitude feedback. This study shows that the direct measurement of the altitude of atmospheric lidar opacity is a good candidate for the necessary observational metric. The opacity altitude is the level at which a spaceborne lidar beam is fully attenuated when probing an opaque cloud. By combining this altitude with the direct lidar measurement of the cloud-top altitude, we derive the effective radiative temperature of opaque clouds which linearly drives (as we will show) the outgoing longwave radiation. We find that, for an opaque cloud, a cloud temperature change of $1 \mathrm{~K}$ modifies its cloud radiative effect by $2 \mathrm{~W} \mathrm{~m}^{-2}$. Similarly, the longwave cloud radiative effect of optically thin clouds can be derived from their top and base altitudes and an estimate of their emissivity. We show with radiative transfer simulations that these relationships hold true at single atmospheric column scale, on the scale of the Clouds and the Earth's Radiant Energy System (CERES) instantaneous footprint, and at monthly mean $2^{\circ} \times 2^{\circ}$ scale. Opaque clouds cover $35 \%$ of the ice-free ocean and contribute to $73 \%$ of the global mean
\end{abstract}

cloud radiative effect. Thin-cloud coverage is $36 \%$ and contributes $27 \%$ of the global mean cloud radiative effect. The link between outgoing longwave radiation and the altitude at which a spaceborne lidar beam is fully attenuated provides a simple formulation of the cloud radiative effect in the longwave domain and so helps us to understand the longwave cloud altitude feedback mechanism.

\section{Introduction}

Cloud feedbacks remain the main source of uncertainty in predictions of climate sensitivity (e.g., Dufresne and Bony, 2008; Vial et al., 2013; Webb et al., 2013; Caldwell et al., 2016). One reason for this uncertainty is that clouds simulated by climate models in the current climate exhibit large biases compared to observations (e.g., Zhang et al., 2005; Haynes et al., 2007; Chepfer et al., 2008; Williams and Webb, 2009; Marchand and Ackerman, 2010; Cesana and Chepfer, 2012, 2013; Kay et al., 2012; Nam et al., 2012; Klein et al., 2013), leading to low confidence in the cloud feedbacks predicted by the models.

To understand feedback mechanisms, it is useful to identify the fundamental variables driving the climate radiative response and then to decompose the overall radiative response as the sum of the individual responses due to changes in each of these variables. This classical feedback analysis has been frequently applied to outputs from numerical cli- 
mate system simulations in order to estimate the effects of changes in water vapor, temperature lapse rate, clouds, and surface albedo on the overall climate radiative response (e.g., Cess et al., 1990; Le Treut et al., 1994; Watterson et al., 1999; Colman, 2003; Bony et al., 2006; Bates, 2007; Soden et al., 2008; Boucher et al., 2013; Sherwood et al., 2015; Rieger et al., 2016). Focusing only on the cloud feedback mechanisms, Zelinka et al. (2012a) and others used this approach to isolate the role of each of the fundamental cloud variables that contribute to the cloud radiative response: cloud cover, cloud optical depth or water phase (liquid or ice), and cloud altitude (or cloud temperature). The shortwave (SW) cloud feedback is primarily driven by changes in cloud cover and cloud optical depth, whereas the longwave (LW) cloud feedback is driven by changes in cloud cover, cloud optical depth, and cloud vertical distribution (e.g., Klein and Jakob, 1999; Zelinka et al., 2012b, 2013, 2016).

Using observations to verify the cloud feedback mechanisms simulated in climate models requires two steps: firstly, establishing a robust link between the observed fundamental cloud variables and the cloud radiative effect (CRE) at the top of the atmosphere (TOA), so that a change in a fundamental cloud variable can be unambiguously related to a change in the CRE at the TOA, and secondly, establishing an observational record of these fundamental cloud variables that is long enough, stable enough, and accurate enough to detect the cloud changes due to greenhouse gas forcing (Wielicki et al., 2013). Such records do not exist yet, but existing records might further our understanding (Klein and Hall, 2015).

This paper focuses on the LW cloud feedback. Current climate models consistently predict that cloud altitude change is the dominant contributor to the LW cloud feedback (Zelinka et al., 2016), consistent with many previous studies (e.g., Schneider, 1972; Cess, 1975; Hansen et al., 1984; Wetherald and Manabe, 1988; Cess et al., 1996; Hartmann and Larson, 2002). While models agree on the sign and the physical mechanism of the LW cloud altitude feedback, they predict different magnitudes. Simulations from the Coupled Model Intercomparison Project Phase 5 (CMIP5) suggest that upper tropospheric clouds will rise by 0.7 to $1.7 \mathrm{~km}$, at all latitudes, in a warmer climate $(+4 \mathrm{~K})$. This is a significant change compared to the currently observed variability and means cloud altitude could be a more robustly observable signature of climate change than the CRE (Chepfer et al., 2014). Nevertheless, the LW cloud altitude feedback mechanism and its magnitude still remain to be confidently verified with observations, because (1) there is no simple, robust, and comprehensive mathematical formulation linking the observed fundamental cloud variables and the LW CRE at the TOA, and (2) there are no sufficiently accurate and stable observations of the vertical distribution of clouds over several decades.

A preliminary step toward observational constraints on LW cloud feedback would be to establish a robust link between the LW CRE at the TOA and a small number of fundamental cloud properties that can be both accurately ob- served and simulated in climate models. In the SW, Taylor et al. (2007) defined such a simplified radiative transfer model by robustly expressing the SW CRE as a function of the cloud cover and the cloud optical depth. This linear relationship has been widely used for decomposing SW cloud feedbacks into contributions from changes in cloud cover and optical depth. Unlike the SW CRE, the LW CRE depends on a third variable, cloud vertical distribution, in addition to cloud cover and optical depth. This makes establishing a simple radiative transfer model that robustly expresses the CRE as a function of a limited number of properties more challenging in the LW than in the SW, as Taylor et al. (2007) and Yokohata et al. (2005) recognized.

Detailed information from active sensors has already been fed into comprehensive radiative transfer simulations to accurately compute the TOA and surface LW CRE in welldefined atmospheric conditions (e.g., Zhang et al., 2004; L'Ecuyer et al., 2008; Kato et al., 2011; Rose et al., 2013). Defining a simple linear formulation linking the LW CRE at the TOA to a limited number of cloud variables would be more directly useful for decomposing cloud climate feedbacks. This formulation, however, cannot utilize the detailed cloud vertical distribution but must be based on specific cloud levels that drive the LW CRE at the TOA. Further, these specific cloud levels must be accurately observable on a global scale from satellites.

Most of the cloud climatologies derived from space observations rely on passive satellites, which do not retrieve the detailed cloud vertical distribution and instead retrieve single-layer effective cloud heights, often summarized as cloud fraction in seven cloud-top pressure bins. Hartmann et al. (1992) used these pressure bins coupled with ranges of cloud optical depth to define different cloud types associated with different values of CRE. These cloud types have been used to analyze the interannual cloud record collected by the Moderate Resolution Imaging Spectroradiometer (MODIS) (e.g., Zelinka and Hartmann, 2011; Zhou et al., 2013; Yue et al., 2017). Recently, Marvel et al. (2015) and Norris et al. (2016) analyzed data from the International Satellite Cloud Climatology Project (ISCCP) and the Pathfinder Atmospheres Extended (PATMOS-x) data sets in terms of these cloud types to search for trends in LW CRE which would be associated with changes in cloud properties.

Today, 10 years of satellite-borne active-sensor data collected by the Cloud-Aerosol LIdar with Orthogonal Polarization (CALIOP) from the Cloud-Aerosol Lidar and Infrared Pathfinder Satellite Observations (CALIPSO; Winker et al., 2010) and the Cloud Profiling Radar (CPR) from CloudSat (Stephens et al., 2002) are available to provide a detailed and accurate view of cloud vertical distribution. Recently, Stephens et al. (2017) used combined passive- and activesensor observations (2B-FLXHR-LIDAR product; Henderson et al., 2013) to rebuild cloud types similar to Hartmann et al. (1992). Stephens et al. (2017) found differences in the attribution of CRE to cloud type compared to Hartmann et 
al. (1992), largely due to ambiguities of passive cloud-top height retrievals in the presence of optically thin and multilayer clouds (e.g., Sherwood et al., 2004; Holz et al., 2008; Mace et al., 2011; Di Michele et al., 2013; Stubenrauch et al., 2013). Data from CALIOP and CloudSat can be used to build, for the first time, a simplified radiative transfer model that robustly expresses the LW CRE as a function of cloud cover, optical depth (or emissivity) and cloud altitude, and that can be tested against observations. In this paper, we summarize the vertical profiles of clouds observed by active sensors using three specific cloud levels that drive the LW CRE at the TOA and that can be accurately observed by spaceborne lidar: cloud-top altitude, cloud-base altitude, and the altitude of opacity, at which the lidar signal becomes fully attenuated within an opaque cloud. This altitude of opacity and the opaque-cloud cover are both observed by spaceborne lidar, and are strongly correlated to the LW CRE (Guzman et al., 2017), because emissions from layers located below the altitude of opacity have little influence on the outgoing LW radiation (OLR). Previous studies (Ramanathan, 1977; Wang et al., 2002) suggested that the link between the opaque-cloud temperature and the OLR is linear, which would be mathematically very convenient for the study of cloud feedbacks (derivatives), but these studies are limited to radiative transfer simulations only. We propose to build on these studies by adding spaceborne lidar information to obtain a simplified radiative transfer model in the LW domain that can give a highly accurate proxy for OLR with a small set of parameters available from both observations (space lidar) and models (space-lidar simulator). This approach is in contrast to reliance on $7 \times 7$ histograms (altitude $\times$ optical depth) of cloud types from ISCCP and use of a matching radiative kernel. Moreover, a highly stable long-time observational record is essential for studying clouds and climate feedback (Wielicki et al., 2013), and current passive instruments have shown limited calibration stability over decadal timescales (e.g., Evan et al., 2007; Norris and Evan, 2015; Shea et al., 2017).

In Sect. 2 we present the data and methods used in this study. In Sect. 3 we define the radiative temperatures of opaque and thin clouds derived from combined lidar observations and reanalysis, and document them over the midlatitudes and the tropics. In Sect. 4 we use radiative transfer simulations to establish a simple expression of the OLR as a function of lidar cloud observations for opaque-cloud single columns and for thin-cloud (nonopaque) single columns, using clear-sky data from the Clouds and the Earth's Radiant Energy System (CERES) satellite instrument. We verify this relationship using CERES and CALIPSO observations, first collocated at the instantaneous $20 \mathrm{~km}$ scale, then monthly averaged on $2^{\circ}$ latitude $\times 2^{\circ}$ longitude grids. In Sect. 5 we estimate the independent contributions to the LW CRE of optically opaque clouds and optically thin clouds. We then focus on the tropics and examine opaque- and thin-cloud CRE partitioned into regions of subsidence and deep convection.
Section 6 discusses the limits of the linear expression we propose, and concluding remarks are summarized in Sect. 7.

\section{Data and method}

\subsection{Opaque- and thin-cloud observations by spaceborne lidar}

Eight years (2008-2015) of CALIPSO observations are used in this study. The GCM-Oriented CALIPSO Cloud Product (GOCCP)-OPAQ (GOCCP v3.0; Guzman et al., 2017) has 40 vertical levels with $480 \mathrm{~m}$ vertical resolution. Every CALIOP single-shot profile - including multilayer profiles is classified into one of three types (Fig. 1).

Clear-sky single column (brown, center) is entirely free of clouds: none of the 40 levels composing the atmospheric single column are flagged as "cloud" (cloud detection information in Chepfer et al., 2010).

Opaque-cloud single column (orange, right) contains a cloud in which the lidar is fully attenuated at an altitude termed $Z_{\text {opaque. Full attenuation of the signal is reached at }}^{\mid}$ a visible optical depth of about 3 to 5 integrated from the TOA (Vaughan et al., 2009). This corresponds to a cloud LW emissivity of 0.8 to 0.9 if we consider that cloud particles do not absorb visible wavelengths and that scattering can be neglected in the LW domain. In GOCCP, such an opaque single column is identified by one level flagged as "z_opaque". Like other variables identified by the superscript "|" in the rest of this paper, $Z_{\text {opaque }}^{\mid}$refers to a single column, i.e., a 1-D atmospheric column from the surface to the TOA where each altitude layer is uniformly filled with molecules and/or

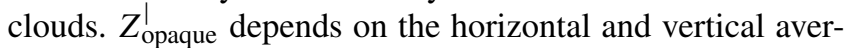
aging used in the retrieval algorithm. It is also affected during the daytime by noise from the solar background. At $480 \mathrm{~m}$ vertical resolution, it depends weakly on the characteristics of the lidar.

Thin-cloud single column (brown and blue, left) contains one or more semi-transparent clouds. In GOCCP, this kind of single column is identified by at least one level flagged as "cloud", but no level is flagged as "z_opaque".

Figure 2 shows the global coverage of these three single column types on $2^{\circ} \times 2^{\circ}$ grids. Global mean opaque-cloud cover $C_{\mathrm{opaque}}^{\boxplus}$ is $35 \%$, thin-cloud cover $C_{\text {thin }}^{\boxplus}$ is $36 \%$, and the clear-sky cover $C_{\text {clear }}^{\boxplus}$ is $29 \% . C_{\mathrm{opaque}}^{\boxplus}, C_{\text {thin }}^{\boxplus}$, and $C_{\text {clear }}^{\boxplus}$ refer to the $2^{\circ} \times 2^{\circ}$ grid box, like any variable identified by the superscript " $\boxplus$ " in the rest of the paper. Opaque-cloud cover is very high at midlatitudes and, in the tropics, high occurrences clearly reveal regions of deep convection (warm pool, ITCZ) and stratocumulus regions at the eastern part of oceans. Thincloud cover is very homogeneous over all oceans, with slight maxima in some regions, near the warm pool. These results are discussed in Guzman et al. (2017).

Our study builds on the work of Guzman et al. (2017) by considering $Z_{\text {opaque }}^{\mid}$in terms of temperature rather than alti- 


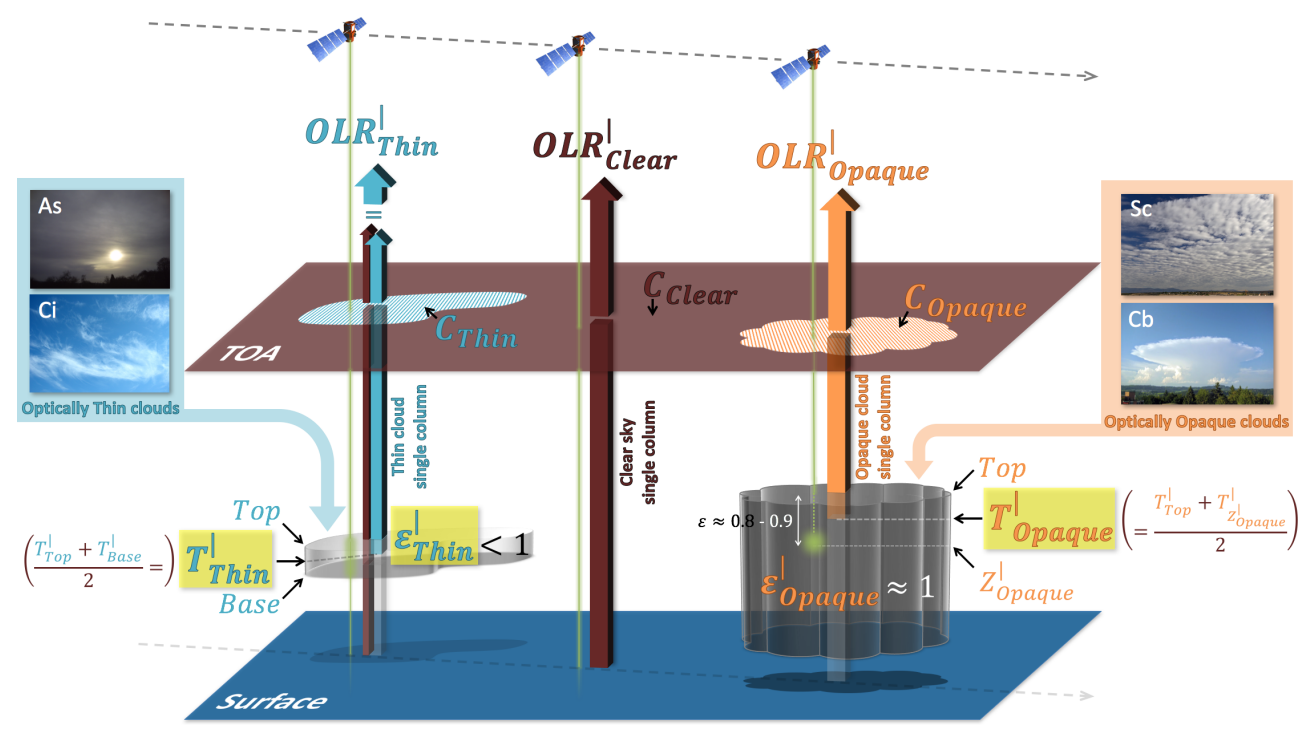

Figure 1. Partitioning of the atmosphere into three single column types thanks to the CALIOP lidar: (left) thin-cloud single column, when a cloud is detected in the lidar signal and the laser beam reaches the surface, (middle) clear-sky single column, when no cloud is detected, and (right) opaque-cloud single column, when a cloud is detected and the laser beam becomes fully attenuated at a level called $Z_{\text {opaque }}^{\mid}$ $C, T$, and $\varepsilon$ account for cover, temperature, and emissivity. Variables highlighted in yellow are the key cloud properties, extracted from GOCCP-OPAQ, that drive OLR over thin-cloud and opaque-cloud single columns. The total gridded OLR will be computed from the three single column OLRs weighted by their respective cover: $C_{\text {thin }}, C_{\text {clear }}, C_{\text {opaque }}$.

tude, and by estimating an additional variable, the thin-cloud emissivity.

Temperatures $T_{Z_{\text {opaque }}^{\mid}}^{\mid}, T_{\text {top }}^{\mid}$, and $T_{\text {base }}^{\mid}$are respectively those at the altitudes of the level flagged as " $z$ opaque" $\left(Z_{\text {opaque }}^{\mid}\right)$and of the highest $\left(Z_{\text {top }}^{\mid}\right)$and lowest $\left(Z_{\text {base }}^{\top}\right)$ levels flagged as "cloud", using temperature profiles from the NASA Global Modeling and Assimilation Office (GMAO) reanalysis (Suarez et al., 2005) provided in CALIOP level 1 data and also reported in GOCCP v3.0 data.

Thin-cloud emissivity $\varepsilon_{\text {thin }}^{\mid}$of a thin-cloud single column is inferred from the attenuated scattering ratio of clear-sky layers measured by the lidar below the cloud. This is approximately equal to the apparent two-way transmittance through the cloud which, considering a fixed multiple-scattering factor $\eta=0.6$, allows retrieval of the thin-cloud visible optical depth $\tau_{\text {thin }}^{\text {VIS }}$ (Garnier et al., 2015). As cloud particles are much larger than the wavelengths of visible and infrared light, and assuming there is no absorption by cloud particles in the visible domain, the thin-cloud LW optical depth $\tau_{\text {thin }}^{\mathrm{LW}}$ is approxi-

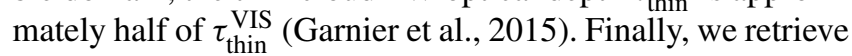
the thin-cloud emissivity as $\varepsilon_{\text {thin }}^{\mid}=1-e^{-\tau_{\text {thin }}^{\mathrm{LW}}}$. Emissivity of opaque clouds cannot be inferred and we assume they are approximately black bodies, i.e., $\varepsilon_{\text {opaque }}^{\mid} \approx 1$.

Our approach takes into account the possibility of multilayer clouds within single columns: $T_{\text {top }}^{\mid}$and $Z_{\text {top }}^{\mid}$refer to the highest level of the highest cloud in the column and $T_{\text {base }}^{\mid}$and $Z_{\text {base }}^{\mid}$to the lowest level of the lowest cloud in the column. In this case, $\varepsilon_{\text {thin }}^{\mid}$is computed from the summed optical depth of all cloud layers in the column.

To avoid the effects of solar background noise, results presented in this paper are only for nighttime conditions. Furthermore, we only consider observations over oceans to avoid uncertainties due to the ground-temperature diurnal cycle over land. In order not to be influenced by major surface changes across seasons, we also removed all observations over sea ice from this study, based on sea ice fraction from the European Centre for Medium-Range Weather Forecasts (ECMWF) ERA-Interim reanalysis (Berrisford et al., 2011).

\subsection{Flux observations collocated with lidar cloud observations}

The CERES radiometer, on board the Aqua satellite, measures the OLR at the location where the CALIOP lidar, on board the CALIPSO satellite, will fire $2 \mathrm{~min}$ and $45 \mathrm{~s}$ later. The instantaneous Single Scanner Footprint (SSF) of the CERES swath crossing the CALIPSO ground-track gives the OLR over atmospheric single columns sounded by the lidar. The CERES footprint has a $\sim 20 \mathrm{~km}$ diameter, while the CALIOP lidar samples every $333 \mathrm{~m}$ along-track with a $90 \mathrm{~m}$ diameter footprint, meaning the lidar can sample up to 60 atmospheric single columns within a single CERES footprint. To collocate the GOCCP-OPAQ instant data and the CERES SSF measurements, we use the CALIPSO, CloudSat, CERES, and MODIS merged product (C3M; Kato et al., 2011) which flags the instantaneous CERES SSF footprints 


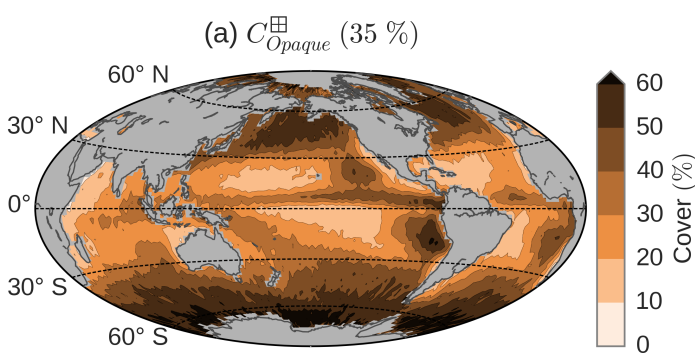

(b) $C_{\text {Thin }}^{\boxplus}(36 \%)$

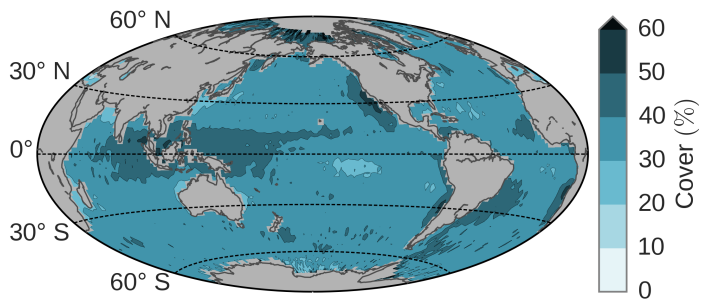

(c) $C_{\text {Clear }}^{\boxplus}(29 \%)$

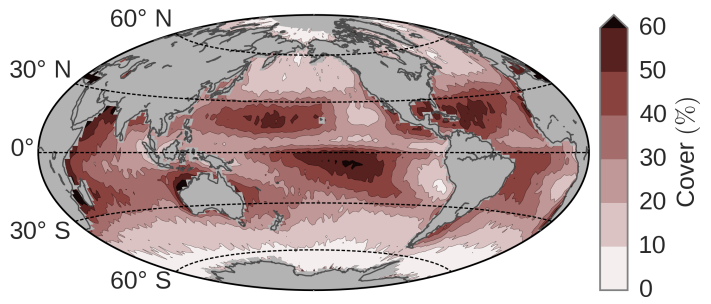

Figure 2. Maps of (a) opaque-cloud cover, (b) thin-cloud cover, and (c) clear-sky cover. Only nighttime over ice-free oceans for the 2008-2015 period is considered. Global mean values are given in parentheses.

where the CERES swath crosses the CALIPSO groundtrack. For each of these flagged CERES SSF footprints, we matched, from geolocation information, all the GOCCPOPAQ single columns falling into the CERES footprint. We consider that an atmospheric column with a CERES footprint base is an opaque (thin) cloud column if all matched single columns are declared as opaque (thin) cloud single column. We then use these opaque- and thin-cloud columns to validate the lidar-derived OLR.

From the C3M product, we also use the estimated clearsky OLR of the instantaneous CERES SSF where the CERES swath crosses the CALIPSO ground-track. This estimated clear-sky OLR is computed from radiative transfer simulations using the synergistic information of the different instruments flying in the Afternoon Train (A-Train) satellite constellation. As C3M only covers the period when both CALIPSO and CloudSat are both fully operational (until April 2011), we also use the clear-sky OLR from $1^{\circ} \times 1^{\circ}$ gridded data monthly mean CERES Energy Balanced and Filled (EBAF) Edition $2.81^{\circ} \times 1^{\circ}$ product (Loeb et al., 2009), which we average over $2^{\circ} \times 2^{\circ}$ grid boxes.

\subsection{Radiative transfer computations}

For all the radiative transfer computations needed in this study, we use the GAME radiative transfer code (Dubuisson et al., 2004) combined with mean sea surface temperature (SST) and atmospheric profiles of temperature, humidity and ozone extracted from the ERA-Interim reanalysis. GAME calculates the radiative flux and radiances over the total solar and infrared spectrum. The radiative transfer equation is solved using Discrete Ordinate Radiative Transfer (DISORT) method (Stamnes et al., 1988), and gaseous absorption is calculated from the $k$-distribution method. The code accounts for scattering and absorption by aerosol and clouds as well as interactions with gaseous absorption. GAME does not take into account cloud 3-D effects, and is based on the planeparallel approximation. In this study, we use GAME to compute integrated OLR between 5 and $100 \mu \mathrm{m}$.

\section{Radiative temperatures of opaque and thin clouds derived from lidar cloud observations and reanalysis}

We define in this section the radiative temperatures of opaque and thin clouds that can be derived from lidar measurements. The cloud radiative temperature corresponds to the equivalent radiative temperature of the cloud $T_{\text {rad }}^{\dagger}$ such that the upward top of the cloud LW radiative flux emitted by the cloud with emissivity $\varepsilon^{\mid}$is $F_{\text {cloud }}^{\uparrow \mathrm{LW} \mid}$ (cloud top) $=\varepsilon^{\mid} \sigma\left(T_{\text {rad }}^{\mid}\right)^{4}$, where $\sigma$ denotes the Stefan-Boltzmann constant. We present distributions of these cloud radiative temperatures derived from lidar measurements over the midlatitudes and the tropics.

\subsection{Definition and approximations of the cloud radiative temperature}

Considering an optically uniform cloud with a cloud total LW optical depth $\tau_{\text {cloud }}^{\mathrm{LW}}$, and assuming a linearly increasing temperature from the cloud top to the cloud base, we can compute the upward LW radiative flux at the cloud top emitted by the cloud $F_{\text {cloud }}^{\uparrow \mathrm{LWl}}$ (cloud top) using the radiative transfer equation (RTE) (see Appendix A). Solving the equation $F_{\text {cloud }}^{\uparrow \mathrm{LW} \mid}($ cloud top $)=\varepsilon^{\mid} \sigma\left(T_{\text {rad }}^{\mid}\right)^{4}=$ $\left(1-e^{-\tau_{\text {cloud }}^{\mathrm{LW} \mid}}\right) \sigma\left(T_{\text {rad }}^{\downarrow}\right)^{4}$, we can infer the value of the equivalent radiative cloud temperature $T_{\text {rad }}^{\mid}$. Figure 3 shows $T_{\text {rad }}^{\mid}$ computed from RTE (green) as a function of $\tau_{\text {cloud }}^{\mathrm{LW} \mid}$. As $\tau_{\text {cloud }}^{\mathrm{LWl}}$ increases, $T_{\text {rad }}^{\mid}$decreases and approaches the cloud-top temperature.

We approximate $T_{\text {rad }}^{\mid}$for opaque clouds and thin clouds using straightforward formulations that can be derived from lidar cloud observations and reanalysis. For the opaque-cloud case (Fig. 1, right), the optically thick cloud completely absorbs upward LW radiative flux propagating from below. In this case, atmospheric layers below $Z_{\text {opaque }}$ have little influ- 


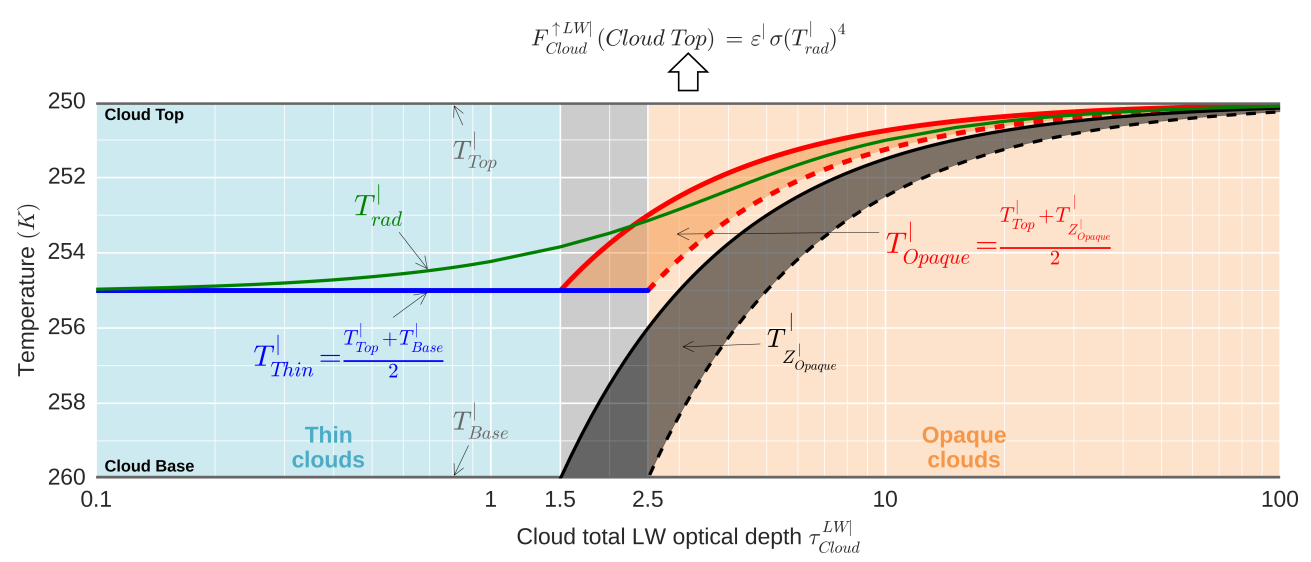

Figure 3. Comparison of (green) the cloud radiative temperature $T_{\text {rad }}^{\mid}$inferred from the RTE (see Appendix A) with the lidar definitions

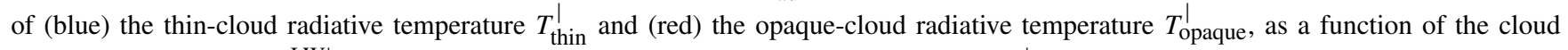
total LW optical depth $\tau_{\text {cloud }}^{\mathrm{LW} \mid}$. Here, on an example with a fixed cloud-top temperature $T_{\text {top }}^{\mid}$at $250 \mathrm{~K}$ and a fixed cloud-base temperature $T_{\text {base }}^{\mid}$at $260 \mathrm{~K} . T_{\text {rad }}^{\mid}$is obtained by computing the LW flux emitted by the cloud at the top $F_{\text {cloud }}^{\uparrow L W \mid}$ (cloud top) from the RTE and solving $F_{\text {cloud }}^{\uparrow \mathrm{LW} \mid}$ (cloud top) $=\varepsilon^{\mid} \sigma\left(T_{\mathrm{rad}}^{\mid}\right)^{4}$. Orange area defines opaque clouds, which in lidar observations have $\tau_{\text {cloud }}^{\mathrm{LW} \mid}$ greater than a limit situated between 1.5 to 2.5 . Below this limit clouds are declared as thin clouds (blue area). Clouds with $\tau_{\text {cloud }}^{\mathrm{LW}}$ between 1.5 and 2.5 could be either opaque or thin clouds (gray area).

ence on $\mathrm{OLR}_{\text {opaque. Therefore, }}^{\mid} \mathrm{OLR}_{\text {opaque }}^{\mid}$is mainly driven by an opaque-cloud radiative temperature defined as

$T_{\text {opaque }}^{\mid}=\frac{T_{\text {top }}^{\mid}+T_{Z_{\text {opaque }}^{\mid}}^{\mid} .}{2}$.

For the thin-cloud case (Fig. 1, left), the cloud is translucent so that a part of the upward LW radiative flux emitted by the surface and cloud-free atmospheric layers underneath the cloud is transmitted through the cloud. In this case, OLR depends on the surface temperature and surface emissivity, the temperature and humidity profiles below the cloud, the cloud emissivity $\varepsilon_{\text {thin }}^{\mid}$, and the thin-cloud radiative temperature defined as

$T_{\text {thin }}^{\mid}=\frac{T_{\text {top }}^{\downarrow}+T_{\text {base }}^{\mid}}{2}$.

$T_{\text {thin }}^{\mid}\left(\tau_{\text {cloud }}^{\mathrm{LW} \mid}<1.5\right.$, blue area in Fig. 3$)$ and $T_{\text {opaque }}^{\mid}\left(\tau_{\text {cloud }}^{\mathrm{LW} \mid}>\right.$ 2.5 , orange area) agree well with $T_{\text {rad }}^{\mid}$(deduced from RTE, green). Clouds with $1.5<\tau_{\text {cloud }}^{\mathrm{LW}}<2.5$ (gray area) can be either thin or opaque clouds depending on the integrated LW optical depth at which $Z_{\text {opaque will occur. In computing }}^{\mid}$ LW radiative flux, we assume the fixed cloud-top temperature $T_{\text {top }}^{\mid}$of $250 \mathrm{~K}$ and fixed cloud-base temperature $T_{\text {base }}^{\mid}$of

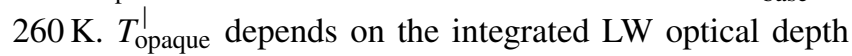
${ }^{\mathrm{LW} \mid}$ from cloud top to $Z_{\text {opaque }}^{\mid}$Since the equivalent visible

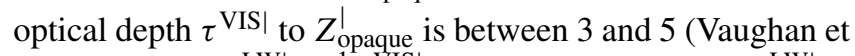
al., 2009), and $\tau^{\mathrm{LW} \mid}=\frac{1}{2} \tau^{\mathrm{VIS} \mid}$ (Chepfer et al., 2014), $\tau^{\mathrm{LW} \mid}$ is known to be between 1.5 and 2.5. This range of optical depth values provides a range of possible values of $T_{Z_{\text {opaque }}^{\mid}}^{\mid}$(black shadow area), and so a range of possible values of $T_{\text {opaque }}^{\dagger}$ (red shadow area).

Computations with other pairs of $T_{\text {top }}^{\mid}$and $T_{\text {base }}^{\mid}$temperatures (not shown) reveal that the relative vertical position of $T_{\text {rad }}^{\mid}$does not depend much on the cloud-top and -base temperatures. In other words, other pairs of $T_{\text {top }}^{\mid}$and $T_{\text {base }}^{\mid}$would produce almost the same figure as Fig. 3, only with the $y$ axis temperature values changed. This means that the difference between $T_{\text {rad }}^{\mid}$and $T_{\text {thin }}^{\mid}$or between $T_{\text {rad }}^{\mid}$and $T_{\text {opaque }}^{\mid}$ becomes larger as the difference between $T_{\text {top }}^{\mid}$and $T_{\text {base }}^{\mid}$increases. Generally, the error made by using specific values of $T_{\text {thin }}^{\mid}$and $T_{\text {opaque }}^{\mid}$in computing $T_{\text {rad }}^{\mid}$also depends on other cloud properties used in the computation, such as cloud inhomogeneity and cloud microphysics. However, this simple theoretical calculation shows that $T_{\text {thin }}^{\mid}$and $T_{\text {opaque }}^{\mid}$as defined above are good approximations of the cloud radiative temperature of the thin and opaque clouds. Considering a cloud with $\tau_{\text {cloud }}^{\mathrm{LW}}>5$ and $10 \mathrm{~K}$ between its base and top temperatures, this approximation leads to an error of the radiative temperature less than $2 \mathrm{~K}$ for a thin cloud and less than $1 \mathrm{~K}$ error for an opaque cloud.

These cloud radiative temperatures are fundamental for studying the LW CRE and are different from the effective radiating temperatures measured by passive instruments, which are influenced by radiation coming from below the cloud. In the case of opaque cloud, which completely absorbs upward LW radiative flux propagating from below, the effective radiating temperature measured by passive instruments should 
agree with the cloud radiative temperature. However, this assumes the knowledge that the cloud is opaque, but cloud emissivity from passive measurements is also sensitive to hypothesis made on the clear-sky and surface property. Unlike passive measurements, lidar measurements robustly separate opaque clouds and thin clouds from the presence or absence of a surface echo (Guzman et al., 2017).

\section{2 $T_{\text {opaque }}^{\mid}$and $T_{\text {thin }}^{\mid}$retrieved from CALIOP observations during 2008-2015}

For each cloudy single column observed by CALIOP, we derive $T_{\text {opaque }}^{\mid}$from $T_{\text {top }}^{\rho}$ and $T_{Z_{\text {opaque }}^{\mid}}^{\mid}$using Eq. (1). We also derive $T_{\text {thin }}^{\mid}$from $T_{\text {top }}^{\mid}$and $T_{\text {base }}^{\mid}$using Eq. (2). We then compute the probability density function (PDF) of $T_{\text {opaque }}^{\mid}$and $T_{\text {thin }}^{\mid}$for three different regions: tropical ascending regions between $\pm 30^{\circ}$ latitude with monthly mean $500 \mathrm{hPa}$ pressure vertical velocity $\omega_{500}<0 \mathrm{hPa} \mathrm{day}^{-1}$, tropical subsidence regions between $\pm 30^{\circ}$ latitude with monthly mean $\omega_{500}>0 \mathrm{hPa}$ day $^{-1}$ and the midlatitudes (north and south) between 65 and $30^{\circ} \mathrm{S}$ and between 30 and $65^{\circ} \mathrm{N}$. To compute these PDFs, e.g., the PDF of $T_{\text {opaque among opaque clouds, we first compute }}^{\dagger}$ the PDF of $T_{\text {opaque }}^{\mid}$using all single columns on each $2^{\circ} \times 2^{\circ}$ grid box for the 2008-2015 period. Then, we compute the PDF with area-weighted average by region, weighting each $2^{\circ} \times 2^{\circ}$ grid box PDF by the ratio of the number of opaque single columns over the number of all single columns. We do this latter weighting in order to take into account sampling differences among the $2^{\circ} \times 2^{\circ}$ grid boxes.

Figure $4 \mathrm{a}$ shows the distributions of $T_{\mathrm{opaque}}^{\mid}$. In tropical subsidence regions (green), $71 \%$ of $T_{\text {opaque }}^{\mid}$are between 0 and $25^{\circ} \mathrm{C}$ with a maximum at $15^{\circ} \mathrm{C}$. Because these clouds are almost as warm as the surface, they do not strongly affect the OLR compared to clear-sky conditions. These clouds are the marine boundary layer clouds present over the descending branches of the Hadley cells. In tropical ascending re-

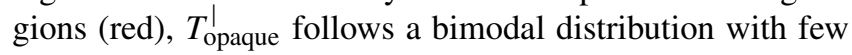
clouds warmer than $0{ }^{\circ} \mathrm{C}(21 \%)$ and most clouds between 0 and $-80^{\circ} \mathrm{C}(79 \%)$. These cold opaque clouds have a very strong local impact on the OLR, since they can be $100 \mathrm{~K}$ colder than the surface skin temperature. However, tropical ascending regions represent about only a fifth of the ocean between $65^{\circ} \mathrm{S}$ and $65^{\circ} \mathrm{N}$, making their global contribution less striking. In the midlatitudes (purple), $T_{\text {opaque }}^{\mid}$are concentrated in a narrower range $\left(20\right.$ to $\left.-60^{\circ} \mathrm{C}\right)$, with temperatures mostly between 10 and $-30^{\circ} \mathrm{C}$. The local radiative effect of these opaque clouds is weaker than the effect if they were in tropical ascending regions. Midlatitudes are, however, a large area $\left(43 \%\right.$ of the ocean surface between $65^{\circ} \mathrm{S}$ and $65^{\circ} \mathrm{N}$ ) and the cover of opaque clouds is large (Fig. 2a). So, their contribution to the global CRE is expected to be large.

The radiative temperature of opaque clouds $T_{\text {opaque }}^{\mid}$is based on the key new lidar information $Z_{\text {opaque (Eq. 1). Fig- }}^{\mid}$
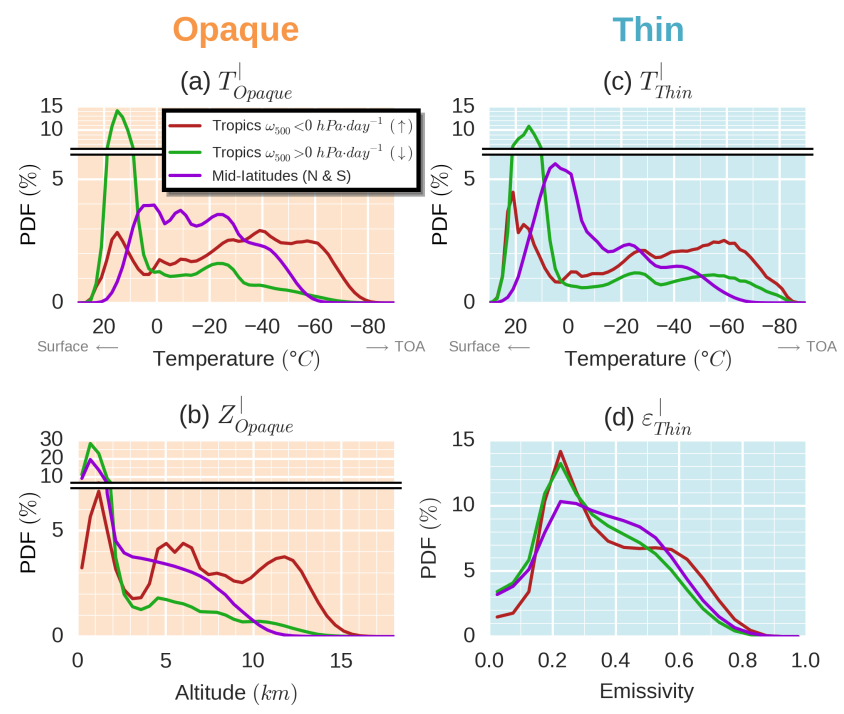

Figure 4. Observed distributions of (a) $T_{\text {opaque among opaque }}^{\mid}$

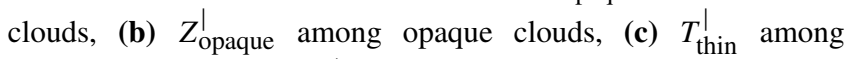
thin clouds, and (d) $\varepsilon_{\text {thin }}$ among thin clouds in three regions: (red) the tropical ascendance $\left[30^{\circ} \mathrm{S}-30^{\circ} \mathrm{N}\right]$ (monthly mean $\left.\omega_{500}<0 \mathrm{hPa} \mathrm{day}^{-1}\right)$, (green) the tropical subsidence $\left[30^{\circ} \mathrm{S}-\right.$ $30^{\circ} \mathrm{N}$ ] (monthly mean $\omega_{500}>0 \mathrm{hPa} \mathrm{day}^{-1}$ ) and (purple) the midlatitudes $\left[30-65^{\circ}\right]$. These regions represent respectively 22,35 , and $43 \%$ of the $\pm 65^{\circ}$ ocean surface. Only nighttime over ice-free oceans for the 2008-2015 period is considered.

ure $4 \mathrm{~b}$ shows that $Z_{\text {opaque }}$ is low for all regions, near $1 \mathrm{~km}$ altitude, especially in subsidence regions. $Z_{\text {opaque }}^{\mid}$are sometimes between 2 and $8 \mathrm{~km}$ in the midlatitude storm track regions. In tropical ascending regions, the PDF is trimodal, with its lowest peak around $1 \mathrm{~km}$ associated with boundary layer clouds and highest peak around $12 \mathrm{~km}$ associated with deep convection systems. The middle mode, near $5 \mathrm{~km}$, might be due to developing convective clouds or middle altitude clouds. Since $T_{\text {opaque }}^{\mid}$also depends on $Z_{\text {top }}^{\mid}$, distributions of the distance between cloud top and $Z_{\text {opaque }}^{\mid}$are given in Fig. B1a (Appendix B).

The radiative temperature of thin clouds $T_{\text {thin }}^{\mid}$is mostly warmer than $0{ }^{\circ} \mathrm{C}$ in tropical subsidence regions (Fig. 4c). $T_{\text {thin }}^{\backslash}$ colder than $-40^{\circ} \mathrm{C}$ occurs more frequently than $T_{\text {opaque }}^{\dagger}$ colder than $-40^{\circ} \mathrm{C}$, suggesting high-altitude optically thin cirrus from detrainments of anvil clouds being generated in adjacent convective regions. In tropical ascending regions, the "warm" mode of the bimodal distributions of $T_{\text {thin }}$ is more populated and warmer than that of $T_{\mathrm{opaque}}^{\mid}$. The main mode of $T_{\text {thin }}^{\mid}$in the midlatitudes is also warmer than that of $T_{\text {opaque }}^{\mid}$. Warmer cloud temperatures, implying smaller CREs, reinforce the importance of the role of the opaque clouds versus thin clouds in the total CRE. Distributions of the distance between top and base for thin clouds are given in Fig. B1b (Appendix B). 
Because the radiative impact of thin clouds will also depend on cloud emissivity, we also compute the distributions of $\varepsilon_{\text {thin }}$ (Fig. 4d). For all regions, the maximum occurs around 0.25: emissivities of thin clouds are usually small, so they have little impact on the OLR and hence their contribution to CRE should be significantly smaller than that of opaque clouds.

\section{Outgoing longwave radiation derived from lidar cloud observations}

In this section, we express the OLR as a function of cloud properties derived from lidar observations $\left(T_{\text {opaque }}^{\mid}, T_{\text {thin }}^{\mid}\right.$, and $\left.\varepsilon_{\text {thin }}^{\mid}\right)$. We evaluate this relationship with observations at an instantaneous $20 \mathrm{~km}$ footprint scale, using high spatial resolution collocated satellite-borne broadband radiometer and lidar data. We also evaluate the relationship at a monthly mean $2^{\circ}$ latitude $\times 2^{\circ}$ longitude gridded scale.

\subsection{Linear relationship deduced from radiative transfer simulations over a single cloudy column}

The goal of this subsection is to establish a simple and robust relationship between (1) the OLR over an opaque-cloud single column OLR $\left.\right|_{\text {opaque }}$ and the radiative temperature $T_{\text {opaque }}^{\mid}$ and, (2) the OLR over a thin-cloud single column OLR $\mathrm{R}_{\text {thin }}$ and the radiative temperature $T_{\text {thin }}^{\mid}$and the thin-cloud emissivity $\varepsilon_{\text {thin }}^{\mid}$.

1. For an opaque-cloud single column, we computed $\mathrm{OLR}_{\text {opaque }}^{\mid}$using direct radiative transfer computations, for various atmospheres containing an opaque cloud with variable altitude and vertical extent. The cloud is represented by a cloud layer with emissivity equal to 1 at $Z_{\text {opaque }}^{\mid}$topped with optically uniform cloud layers with vertically integrated visible optical depth equal to 3.2 , which corresponds to $\varepsilon \approx 0.8$. Dots in Fig. 5a show the obtained OLR $\mathrm{R}_{\text {opaque }}$ as a function of $T_{\text {opaque }}^{\mid}$for tropical atmosphere conditions. Linear regression (solid line) leads to

$\mathrm{OLR}_{\mathrm{opaque}}^{\mid(\mathrm{LID})}=2.0 T_{\mathrm{opaque}}^{\mid}-310$,

where OLR $\mathrm{R}_{\text {opaque }}^{\mid(\text {LID })}$ is expressed in $\mathrm{W} \mathrm{m}^{-2}$ and $T_{\text {opaque }}^{\mid}$in

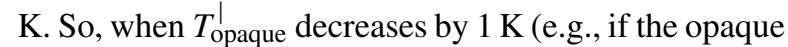
cloud rises up), then the OLR decreases by $2 \mathrm{~W} \mathrm{~m}^{-2}$. This linear relationship, initially pointed out by $\mathrm{Ra}-$ manathan (1977), has a slope which is consistent with a previous work that found $2.24 \mathrm{~W} \mathrm{~m}^{-2} \mathrm{~K}^{-1}$ (Wang et al., 2002, using the radiative transfer model of Fu and Liou, 1992, 1993, and the analysis of Kiehl, 1994). Conducting the same linear regression on very different atmospheric conditions (from tropical to polar) gives similar coefficients. This means that OLR $\left.\right|_{\text {opaque depends mainly }}$ on $T_{\text {opaque }}^{\mid}$This remarkable result demonstrates that a cloud property driving the OLR can be derived from spaceborne lidar measurement. Differences between the computed OLR and the black body emission (dashed line in Fig. 5a) represent the extinction effect of the atmospheric layers above the cloud.

2. For a thin-cloud single column, we can consider that OLR $_{\text {thin }}^{\mid}$is composed of two parts (Fig. 1). The first part, coming from the LW flux emitted by the cloud, can be expressed in the same way as Eq. (3) using $T_{\text {thin }}^{\mid}$ instead of $T_{\text {opaque }}^{\mid}$, and weighted by the thin-cloud emissivity $\varepsilon_{\text {thin }}^{\mid}$. The second part is equal to the OLR over a clear-sky single column OLR $\left.\right|_{\text {clear }} ^{\mid}$(the same single column without the cloud) multiplied by the cloud transmissivity $\left(1-\varepsilon_{\text {thin }}^{\prime}\right)$ :

$$
\begin{aligned}
\mathrm{OLR}_{\text {thin }}^{\mid(\mathrm{LID})} & =\varepsilon_{\text {thin }}^{\mid}\left(2.0 T_{\text {thin }}^{\mid}-310\right) \\
& +\left(1-\varepsilon_{\text {thin }}^{\mid}\right) \mathrm{OLR}_{\text {clear }}^{\mid}
\end{aligned}
$$

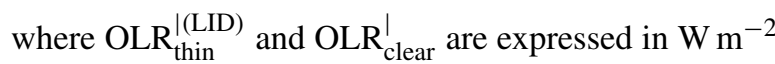
and $T_{\text {thin }}^{\mid}$in $\mathrm{K}$. In order to evaluate this expression and to examine the dependence of OLR $\left.\right|_{\text {thin }} ^{\mid}$to $T_{\text {thin }}^{\mid}$and $\varepsilon_{\text {thin }}^{\mid}$, we computed $\mathrm{OLR}_{\text {thin }}^{\mid}$using direct radiative transfer computations for various atmospheres containing a thin cloud (represented by optically uniform cloud layers with integrated emissivities equal to $\varepsilon_{\text {thin }}$ ) with different altitudes, vertical extents, and emissivities. Dots in Fig. 5b show the resulting OLR ${ }_{\text {thin }}^{\mid}$as a function of $T_{\text {thin }}^{\mid}$ for four different values of $\varepsilon_{\text {thin }}$ in tropical atmosphere conditions. We compare these results with the linear expression of Eq. (4) (solid lines), in which OLR $\mathrm{C}_{\text {clear }}$ is computed for a single column without cloud. The theoretical formulation agrees quite well with the different simulations. This formulation seems to overestimate $\mathrm{OLR}_{\text {thin }}^{\mid}$(up to $+10 \mathrm{~W} \mathrm{~m}^{-2}$ ) in many cases. Reasons for it are discussed in Sect. 6.

\subsection{Evaluation of the linear relationship using observations at instantaneous CERES footprint scale}

We evaluate the robustness of the OLR expressions (Eqs. 3 and 4$)$ at the resolution of a CERES footprint $(\sim 20 \mathrm{~km})$ using CERES measurements and cloud properties derived from collocated CALIOP observations $T_{\text {opaque }}^{\oslash}, T_{\text {thin }}^{\oslash}$ and $\varepsilon_{\text {thin }}^{\oslash}$. For this purpose, we apply Eqs. (3) and (4) using $T_{\text {opaque }}^{\oslash}, T_{\text {thin }}^{\ominus}$, $\varepsilon_{\text {thin }}^{\oslash}$ and the estimated OLR over the scene without the clouds $\mathrm{OLR}_{\text {clear }}^{\oslash}$ is given by C3M. $T_{\text {opaque }}^{\oslash}, T_{\text {thin }}^{\oslash}$, and $\varepsilon_{\text {thin }}^{\oslash}$ refer to an atmospheric column with a CERES footprint base (identified by the superscript " $\oslash$ ") and are obtained by averaging all $T_{\text {opaque }}^{\mid}, T_{\text {thin }}^{\mid}$, and $\varepsilon_{\text {thin }}^{\mid}$within the CERES footprint. OLR ${ }_{\text {clear }}^{\oslash}$, 
(a) Opaque cloud

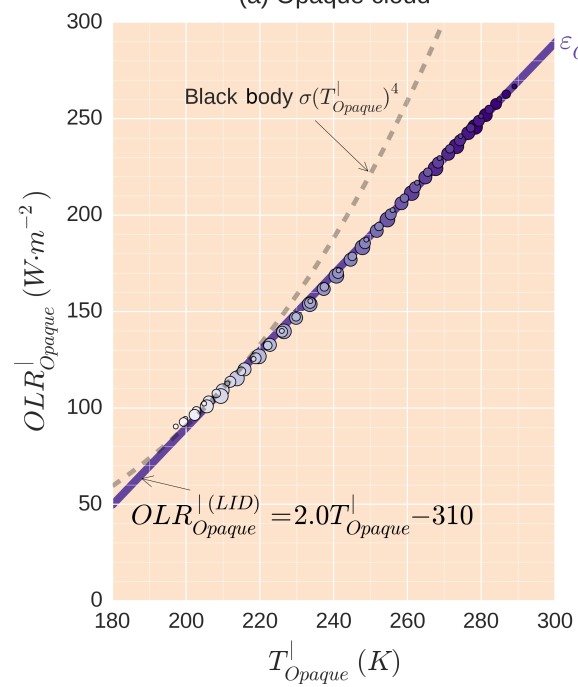

(b) Thin cloud

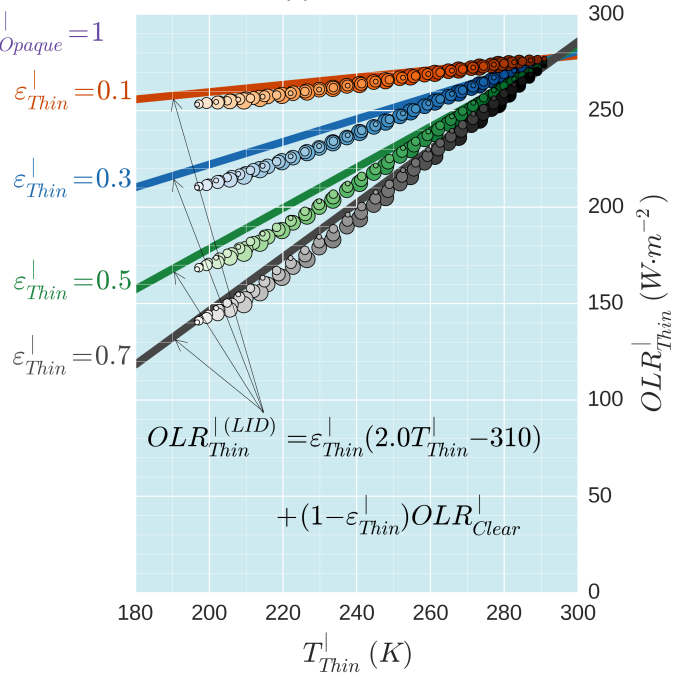

Figure 5. Relationship between the OLR and the cloud radiative temperature from radiative transfer computations: (a) over an opaque-cloud single column and (b) over a thin-cloud single column. Direct radiative transfer computations are shown in dots. Solid lines represent the linear relationships inferred from a regression on dots in the opaque case and applied to the thin-cloud case according to Eq. (4). For a fixed value of cloud emissivity (dots colors; 1 [purple] for opaque clouds and 0.1 [reds], 0.3 [blues], 0.5 [greens], 0.7 [greys] for thin clouds), the linear relationship does not depend on the cloud altitudes (dots light intensity; $0 \mathrm{~km}$ [dark] - $16 \mathrm{~km}$ [bright]) or geometrical thickness (dots size; $1 \mathrm{~km}$ [small] - $5 \mathrm{~km}$ [large]). Results shown here use the year 2008 mean thermodynamic atmospheric variables over the tropics $\left[30^{\circ} \mathrm{S}-30^{\circ} \mathrm{N}\right]$ from ERA-I reanalysis.

$\mathrm{OLR}_{\text {opaque }}^{\oslash}$, and $\mathrm{OLR}_{\text {thin }}^{\oslash}$ refer to atmospheric columns with a CERES footprint base.

Figure 6 compares lidar-derived and observed OLR dur-

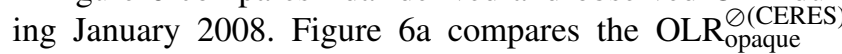
measured by CERES over footprints entirely covered by an opaque cloud, with the OLR $\mathrm{opaque}_{\text {(LID) }}$ computed from $T_{\text {opaque }}^{\oslash}$ using Eq. (3). We see a very strong correlation between observed and computed OLR $(R=0.95)$. This confirms that the OLR over an opaque cloud is linearly dependent on $T_{\text {opaque }}^{\ominus}$, and that it is possible to derive a cloud property which is proportional to the OLR from the lidar measurement. Monitoring $T_{\text {opaque }}^{\mid}$in the long-term should provide important information for a better understanding of the LW cloud feedback mechanism.

Figure $6 \mathrm{~b}$ is the same as Fig. 6a but only CERES footprints entirely covered by a thin cloud are used. OLR $\mathrm{R}_{\text {thin }}^{\oslash(\mathrm{LID})}$, computed from $T_{\text {thin }}^{\oslash}, \varepsilon_{\text {thin }}^{\oslash}$, and OLR $\mathrm{OL}_{\text {clear }}^{\oslash}$ using Eq. (4), correlates well with $\operatorname{OLR}_{\text {thin }}^{\oslash \text { (CERES) }}(R=0.89)$, but the regression line slightly differs from the identity line. Possible reasons for disagreements between both values are discussed in Sect. 6. These same results are also shown as a function of $T_{\text {thin }}^{\oslash}$ and $\varepsilon_{\text {thin }}^{\oslash}$ in Fig. E1 for a fixed value of OLR ${ }_{\text {clear }}^{\oslash}$ (we selected measurements where $\operatorname{OLR}_{\text {clear }}^{\oslash} \in[275,285] \mathrm{W} \mathrm{m}^{-2}$ ) in order to show the effect of those two cloud properties on $\mathrm{OLR}_{\text {thin }}^{\oslash(\mathrm{CERES})}$.
The same evaluation performed with July 2008 data (not shown) gives similar results, with $R=0.96$ for opaque clouds and $R=0.90$ for thin clouds.

\subsection{Evaluation of the linear relationship using observations at monthly mean $2^{\circ} \times 2^{\circ}$ gridded scale}

We first compute the monthly mean gridded total OLR from gridded lidar cloud properties:

$$
\begin{aligned}
\mathrm{OLR}_{\text {total }}^{\boxplus(\mathrm{LID})} & =C_{\text {clear }}^{\boxplus} \mathrm{OLR} \\
& +C_{\text {thin }}^{\boxplus} \mathrm{OLR} \\
\text { clear } & \boxplus(\mathrm{LID})
\end{aligned}
$$

where $C_{\text {clear }}^{\boxplus}, C_{\text {opaque }}^{\boxplus}$, and $C_{\text {thin }}^{\boxplus}$ are the monthly mean covers (Figs. 1,2): the ratio between the number of a specific kind of single column and the total number of single columns that fall into the grid box during a month. $\mathrm{OLR}_{\mathrm{opaque}}^{\boxplus(\mathrm{LI})}$ is computed from $T_{\text {opaque }}^{\boxplus}$ using Eq. (3), and OLR $\mathrm{R}_{\text {thin }}^{\boxplus(L I D)}$ is computed from $T_{\text {thin }}^{\boxplus}, \varepsilon_{\text {thin }}^{\boxplus}$, and OLR ${ }_{\text {clear }}^{\boxplus}$ using Eq. (4). $T_{\text {opaque }}^{\boxplus}, T_{\text {thin }}^{\boxplus}$, and $\varepsilon_{\text {thin }}^{\boxplus}$ are obtained by averaging respectively all $T_{\text {opaque }}^{\mid}, T_{\text {thin }}^{\mid}$, and $\varepsilon_{\text {thin }}^{\mid}$within the $2^{\circ} \times 2^{\circ}$ box.

We then evaluate the lidar-derived OLR ${ }_{\text {total }}^{\boxplus(L I D)}$ against the CERES measurements OLR $\mathrm{H}_{\text {total }}^{\boxplus(C E R E S)}$. To do so, we computed the 2008-2010 mean OLR $\mathrm{t}_{\text {total }}^{\boxplus(L I D)}$ from Eq. (5) using $\mathrm{OLR}_{\text {clear }}^{\boxplus}$ from $\mathrm{C} 3 \mathrm{M}$ and compared it with the one measured by CERES-Aqua. Figure 7 shows the comparison between the computed $\operatorname{OLR}_{\text {total }}^{\boxplus(L I D)}$ (Fig. 7a) and the 
(a) Opaque cloud

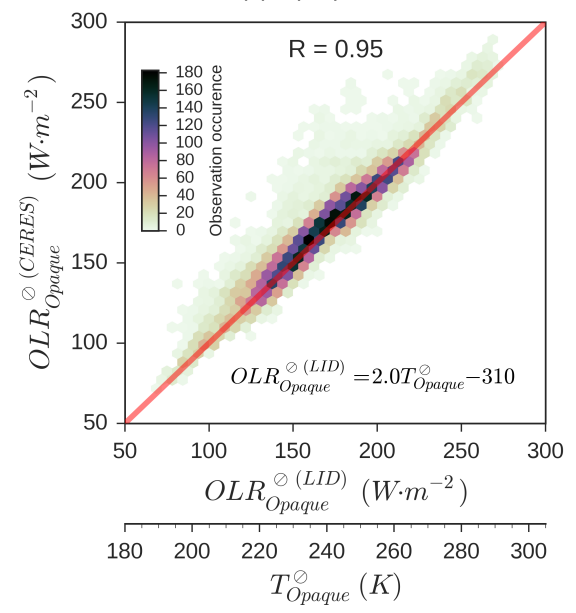

(b) Thin cloud

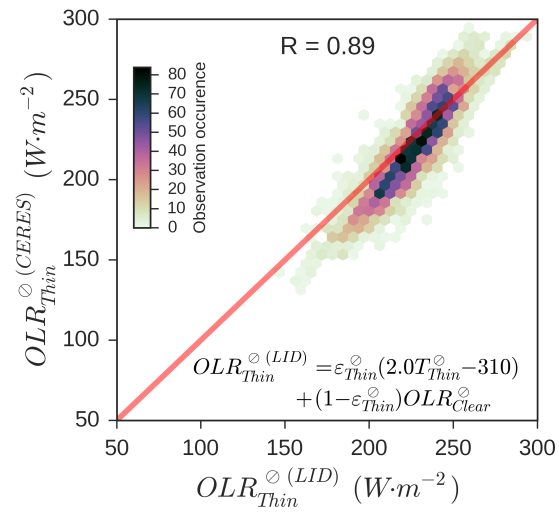

Figure 6. Comparison between observed and lidar-derived OLR at CERES footprint scale: (a) over opaque-cloud single columns and (b) over thin-cloud single columns. Results obtained from CERES ( $y$ axis) and CALIOP ( $x$ axis) collocated measurements. OLR $\mathrm{Oppaque}^{\ominus(\mathrm{LID})}$ and OLR thin $_{\text {(LID) }}$ are computed using Eqs. (4) and (5). Only nighttime conditions over ice-free oceans for January 2008 are considered. $R$ is the correlation coefficient.

measured OLR $\mathrm{total}^{\boxplus(\mathrm{CERES})}$ (Fig. 7b). We first note the agreement of OLR patterns. Figure $7 \mathrm{c}$ shows the difference between those two maps. The global mean difference is $-0.1 \mathrm{~W} \mathrm{~m}^{-2}$ : OLR $\mathrm{R}_{\text {total }}^{\boxplus(\mathrm{LID})}$ very slightly underestimates the observed $\mathrm{OLR}_{\text {total }}^{\boxplus(\mathrm{CERES})}$. The zonal mean differences (not shown) are mostly lower than $2 \mathrm{~W} \mathrm{~m}^{-2}$ and never exceed $5 \mathrm{~W} \mathrm{~m}^{-2}$. Locally, we note a lack of OLR over the warm pool, the intertropical convergence zone (ITCZ) and the stratocumulus regions off the western coast of continents (up to $6-8 \mathrm{~W} \mathrm{~m}^{-2}$ ) and an excess of OLR over latitudes beyond $50^{\circ} \mathrm{N}$ or $40^{\circ} \mathrm{S}$ (up to $4-6 \mathrm{~W} \mathrm{~m}^{-2}$ ). As C3M only covers through April 2011, but we aim to use this framework on long time-series observations, we replace $\mathrm{OLR}_{\text {clear }}^{\boxplus}$ from $\mathrm{C} 3 \mathrm{M}$ with $\mathrm{OLR}_{\text {clear }}^{\boxplus}$ from CERES-EBAF in the rest of this paper. Using OLR ${ }_{\text {clear }}^{\boxplus}$ from C3M instead of CERES-EBAF increases the global mean $\mathrm{OLR}_{\text {total }}^{\boxplus(\mathrm{LID})}$ by $0.6 \mathrm{~W} \mathrm{~m}^{-2}$ (Fig. E2) for reasons discussed in Sect. 6 .

\section{Contributions of opaque clouds and thin clouds to the cloud radiative effect}

In the previous section, we found a linear relationship between $\mathrm{OLR}_{\text {opaque }}$ and $T_{\text {opaque }}$ on different scales. The relationship for thin clouds, though quite simple, is not linear and agrees less with observations than with opaque clouds. In this section, we evaluate the contributions of opaque clouds and thin clouds to the total CRE.

\subsection{Partitioning cloud radiative effect into opaque CRE and thin CRE}

Using Eq. (5), we can decompose the total CRE at the TOA, computed from lidar observations, in opaque- and thin-cloud contributions:

$$
\begin{gathered}
\mathrm{CRE}_{\text {total }}^{\boxplus(\mathrm{LID})}=\mathrm{OLR}_{\text {clear }}^{\boxplus}-\mathrm{OLR}_{\text {total }}^{\boxplus(\mathrm{LID})} \\
=\underbrace{\underbrace{\boxplus}_{\text {opaque }}\left(\mathrm{OLR}_{\text {clear }}^{\boxplus}-\mathrm{OLR}_{\text {opaque }}^{\boxplus(\mathrm{LID})}\right)}_{\mathrm{CRE}_{\text {opaque }}^{\boxplus(\mathrm{LID})}} \\
+\underbrace{C_{\text {thin }}^{\boxplus}\left(\mathrm{OLR}_{\text {clear }}^{\boxplus}-\mathrm{OLR}_{\text {thin }}^{\boxplus(\mathrm{LID})}\right)}_{\mathrm{CRE}_{\text {thin }}^{\boxplus(\mathrm{LID})}} .
\end{gathered}
$$

Thereby, using Eq. (3), we can express $\mathrm{CRE}_{\text {opaque }}^{\boxplus(\mathrm{LID})}$ as a function of $C_{\text {opaque }}^{\boxplus}, T_{\text {opaque }}^{\boxplus}$, and $\mathrm{OLR}_{\text {clear }}^{\boxplus}$ :

$\mathrm{CRE}_{\text {opaque }}^{\boxplus(\mathrm{LID})}=C_{\text {opaque }}^{\boxplus}\left(\mathrm{OLR}_{\text {clear }}^{\boxplus}-2.0 T_{\text {opaque }}^{\boxplus}+310\right)$,

where $\mathrm{CRE}_{\text {opaque }}^{\boxplus(\mathrm{LID})}$ and $\mathrm{OLR}_{\text {clear }}^{\boxplus}$ are expressed in $\mathrm{W} \mathrm{m}^{-2}$ and $T_{\text {opaque }}^{\boxplus}$ in K.

Using Eq. (4), we can express $\mathrm{CRE}_{\text {thin }}^{\boxplus(\mathrm{LID})}$ as a function of $C_{\text {thin }}^{\boxplus}, T_{\text {thin }}^{\boxplus}, \varepsilon_{\text {thin }}^{\boxplus}$, and $\mathrm{OLR}_{\text {clear }}^{\boxplus}$ :

$\mathrm{CRE}_{\text {thin }}^{\boxplus(\mathrm{LID})}=C_{\text {thin }}^{\boxplus} \varepsilon_{\text {thin }}^{\boxplus}\left(\mathrm{OLR}_{\text {clear }}^{\boxplus}-2.0 T_{\text {thin }}^{\boxplus}+310\right)$,

where $\mathrm{CRE}_{\text {thin }}^{\boxplus(\mathrm{LID})}$ and $\mathrm{OLR}_{\text {clear }}^{\boxplus}$ are expressed in $\mathrm{W} \mathrm{m}^{-2}$ and $T_{\text {thin }}^{\boxplus}$ in K. 

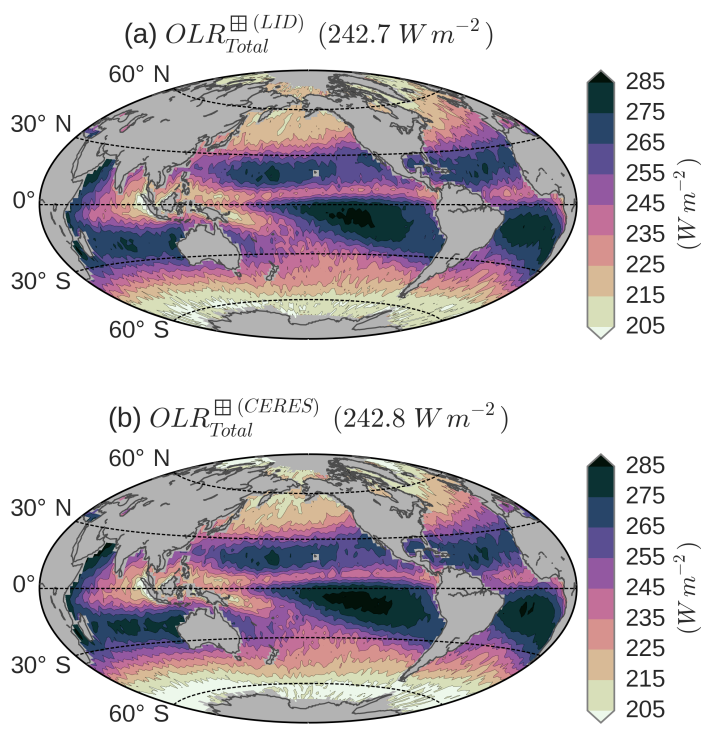

(c) $O L R_{\text {Total }}^{\boxplus(L I D)}-O L R_{\text {Total }}^{\boxplus(C E R E S)}\left(-0.1 \mathrm{Wm}^{-2}\right)$

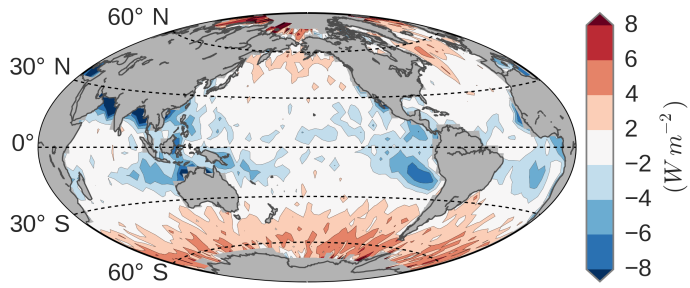

Figure 7. Comparison between observed and lidar-derived OLR at $2^{\circ} \times 2^{\circ}$ gridded scale: (a) derived from CALIOP observations and (b) measured by CERES-Aqua. (c) is (a) minus (b). Only nighttime conditions over ice-free oceans for the 2008-2010 period are considered. Global mean values are given in parentheses.

\subsection{Global means of the opaque-cloud CRE and the thin-cloud CRE}

Figure 8 shows the zonal mean observations of the five cloud properties $\left(C_{\text {opaque }}^{\boxplus}, T_{\text {opaque }}^{\boxplus}, C_{\text {thin }}^{\boxplus}, T_{\text {thin }}^{\boxplus}\right.$, and $\left.\varepsilon_{\text {thin }}^{\boxplus}\right)$. Over the subsidence branches of the Hadley cell, around $20^{\circ} \mathrm{S}$ and $20^{\circ} \mathrm{N}, C_{\text {opaque }}^{\boxplus}$ is minimum (Fig. 8a), $T_{\text {opaque }}^{\boxplus}$ and $T_{\text {thin }}^{\boxplus}$ are warm (Fig. 8b, temperatures in $y$ axis oriented downward) and $\varepsilon_{\text {thin }}^{\boxplus}$ is minimum (Fig. 8c). So, we do not expect a large contribution to the CRE from these regions. In contrast, the intertropical convergence zone (ITCZ) corresponds to local maxima of opaque- and thin-cloud covers, extremely cold $T_{\text {opaque }}^{\boxplus}$ and $T_{\text {thin }}^{\boxplus}$ and a maximum of $\varepsilon_{\text {thin }}^{\boxplus}$. A large CRE is therefore expected from this region. There are always more opaque clouds than thin clouds in the extratropics (beyond $30^{\circ}$ latitude) and they are colder than the thin clouds. It is the opposite in the tropical belt: there are always more thin clouds than opaque clouds, and those are slightly warmer. This suggests that the relative contribution of the thin clouds to the CRE is larger in the tropics than in the rest of the globe. This should not be very dependent on a specific year since
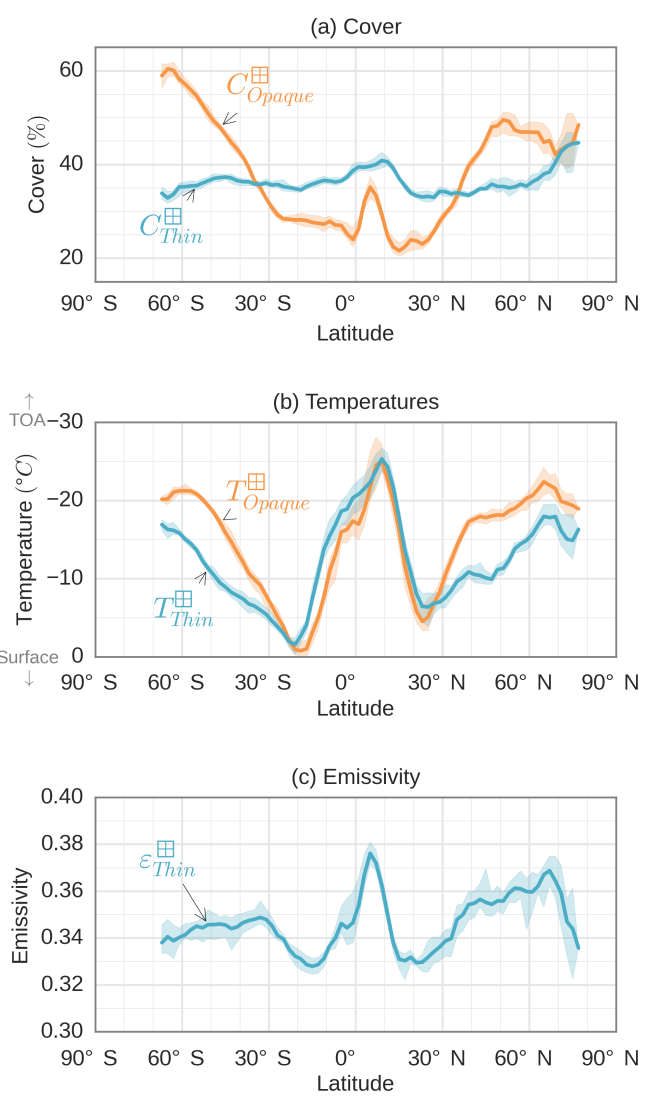

Figure 8. Zonal mean observations: (a) $C_{\mathrm{opaque}}^{\boxplus}$ and $C_{\text {thin }}^{\boxplus}$, (b) $T_{\text {opaque }}^{\boxplus}$ among opaque clouds and $T_{\text {thin }}^{\boxplus}$ among thin clouds and (c) $\varepsilon_{\text {thin }}^{\boxplus}$ among thin clouds. Only nighttime conditions over ice-free oceans for the 2008-2015 period are considered. Shaded areas represent the envelope ( $\max$ to $\mathrm{min}$ ) including interannual variations.

the interannual variations of these five cloud properties (represented by the shaded areas) are very small compared to the zonal differences.

Figure 9 shows that opaque clouds contribute the most $(73 \%)$ to the total CRE. We can also note that the zonal variations of $\mathrm{CRE}_{\text {opaque }}^{\boxplus(\mathrm{LID})}$, and so approximately the variations of $\mathrm{CRE}_{\text {total }}^{\boxplus(\mathrm{LID})}$ (black line), can be explained by the zonal variations of $T_{\text {opaque }}^{\boxplus}$ and $C_{\text {opaque }}^{\boxplus}$ (Fig. 8a, b). For example, the absolute maximum CRE at $5^{\circ} \mathrm{N}\left(\sim 44 \mathrm{~W} \mathrm{~m}^{-2}\right)$ is associated with a large cover and low temperature of opaque clouds. As suggested earlier, the relative contribution of thin clouds $\left(\mathrm{CRE}_{\text {thin }}^{\boxplus(\mathrm{LID})} / \mathrm{CRE}_{\text {total }}^{\boxplus(\mathrm{LID})}\right.$, Fig. 9b) is larger in the tropics, approximately twice as large below $30^{\circ}$ (up to $40 \%$ ) than beyond those latitudes.

Figure 10 shows the same CRE partitioning on maps. The similarity of patterns between total CRE (Fig. 10a) and the opaque clouds CRE contribution (Fig. 10b) is obvious, showing again that opaque clouds mostly drive the CRE. The contribution of thin clouds to the CRE (Fig. 10c) is quite large between $20^{\circ} \mathrm{S}$ and $20^{\circ} \mathrm{N}$ in the Indian Ocean and the western 

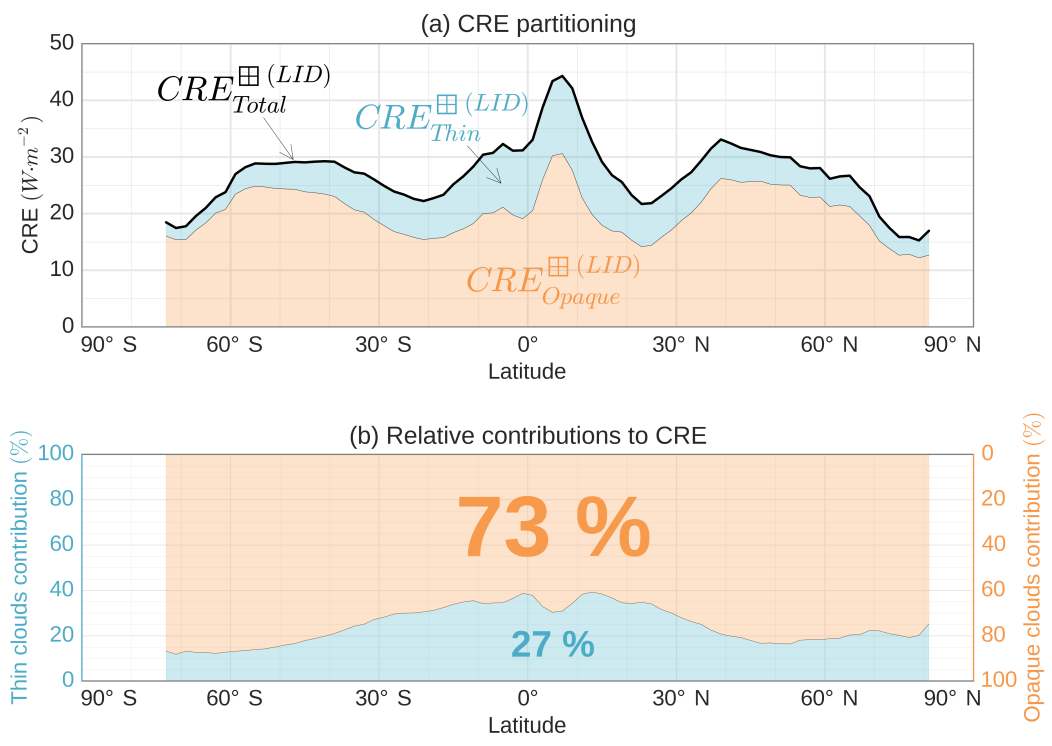

Figure 9. (a) Partitioning of total CRE into opaque CRE and thin CRE. (b) Ratios of the opaque and thin CRE to the total CRE. Only nighttime conditions over ice-free oceans for the 2008-2015 period are considered.

Pacific Ocean, especially all around Indonesia, where $C_{\text {thin }}^{\boxplus}$ (Fig. 2b) is maximum and $T_{\text {thin }}^{\boxplus}$ minimum (not shown).

Globally, the predominance of $\mathrm{CRE}_{\text {opaque }}^{\boxplus(\mathrm{LID})}$ is obvious since it represents nearly three-quarters of the total $\mathrm{CRE}_{\text {total }}^{\boxplus(\mathrm{LID})}$. Thereby, the cloud property $T_{\mathrm{opaque}}^{\boxplus}$ inferred from lidar observations and linearly linked to $\mathrm{OLR}_{\mathrm{opaque}}^{\boxplus}$ should be a very good candidate for constraining LW cloud feedbacks, since thin clouds only account for $27 \%$ of $\mathrm{CRE}_{\text {total }}^{\boxplus(\mathrm{LID})}$. However, since the OLR expression above thin clouds is almost as good as for opaque clouds, it could also be used in a future work to quantify the impact of changes in $C_{\text {thin }}^{\boxplus}, T_{\text {thin }}^{\boxplus}$, and $\varepsilon_{\text {thin }}^{\boxplus}$ on the variations of $\mathrm{CRE}_{\text {thin }}^{\boxplus(\mathrm{LID})}$.

\subsection{Tropical opaque-cloud CRE and thin-cloud CRE in dynamical regimes}

Figure 11 shows the cloud properties as a function of dynamical regime in the tropics (PDF according to the $500 \mathrm{hPa}$ pressure velocity is given Fig. 11h). In tropical convection $\left(\omega_{500}<0 \mathrm{hPa} \mathrm{day}^{-1}\right), C_{\mathrm{opaque}}^{\boxplus}$ is strongly driven by the velocity of ascending air ( 25 to $45 \%$ increase from 0 to $-100 \mathrm{hPa} \mathrm{day}^{-1}$ ), whereas $C_{\text {thin }}^{\boxplus}$ seems to be poorly dependent on it, with an almost constant cover around $40 \%$. In subsidence, the mean $C_{\text {opaque }}^{\boxplus}$ also increases when the air descending velocity is larger but with a wide range of variation from month to month (Fig. 11a). More strikingly, $T_{\text {opaque }}^{\boxplus}$ and $T_{\text {thin }}^{\boxplus}$ (Fig. 11 b) vary linearly with $\omega_{500}$, with a small variability from month to month. $T_{\text {opaque }}^{\boxplus}$ and $T_{\text {thin }}^{\boxplus}$ linearly decrease from 20 to $-100 \mathrm{hPa} \mathrm{day}^{-1}$ from approximately 5 to $-35^{\circ} \mathrm{C}$ and are constant between 20 and $70 \mathrm{hPaday}^{-1}$ at $5^{\circ} \mathrm{C}$. This suggests that, locally, $T_{\text {opaque }}^{\boxplus}$ and $T_{\text {thin }}^{\boxplus}$ are invariant in each

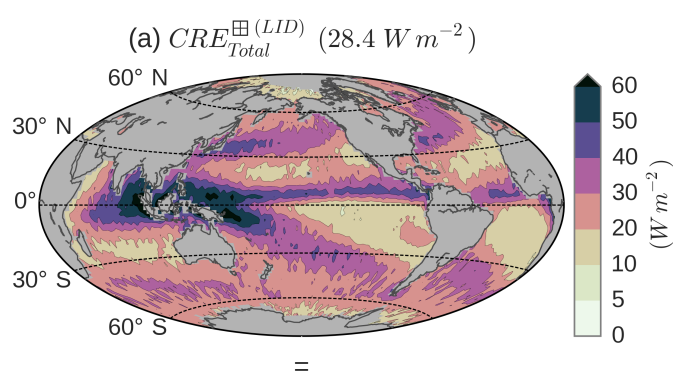

(b) $C R E_{\text {Opaque }}^{\boxplus(L I D)}\left(20.7 \mathrm{~W} \mathrm{~m}^{-2}\right)$

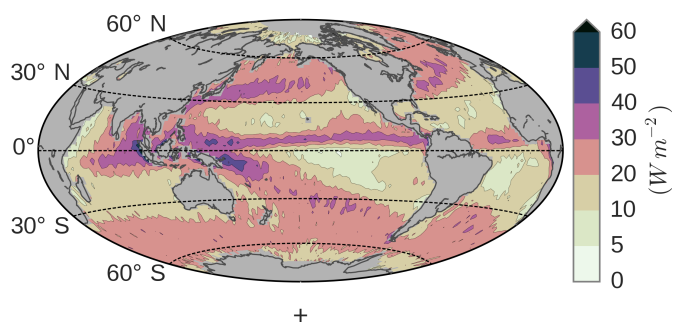

(c) $C R E_{\text {Thin }}^{\boxplus(L I D)}\left(7.7 \mathrm{Wm}^{-2}\right)$

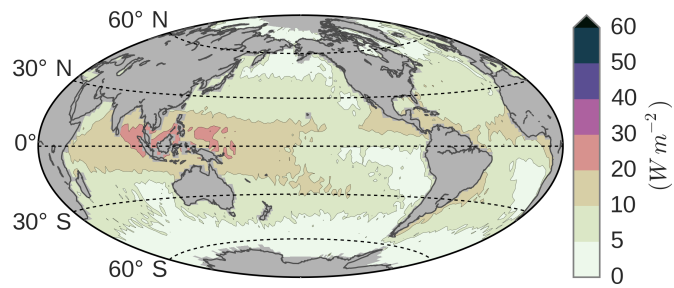

Figure 10. Maps of (a) the total CRE (b) the opaque CRE and (c) the thin CRE. Only nighttime conditions over ice-free oceans for the 2008-2015 period are considered. Global mean values are given in parentheses. 

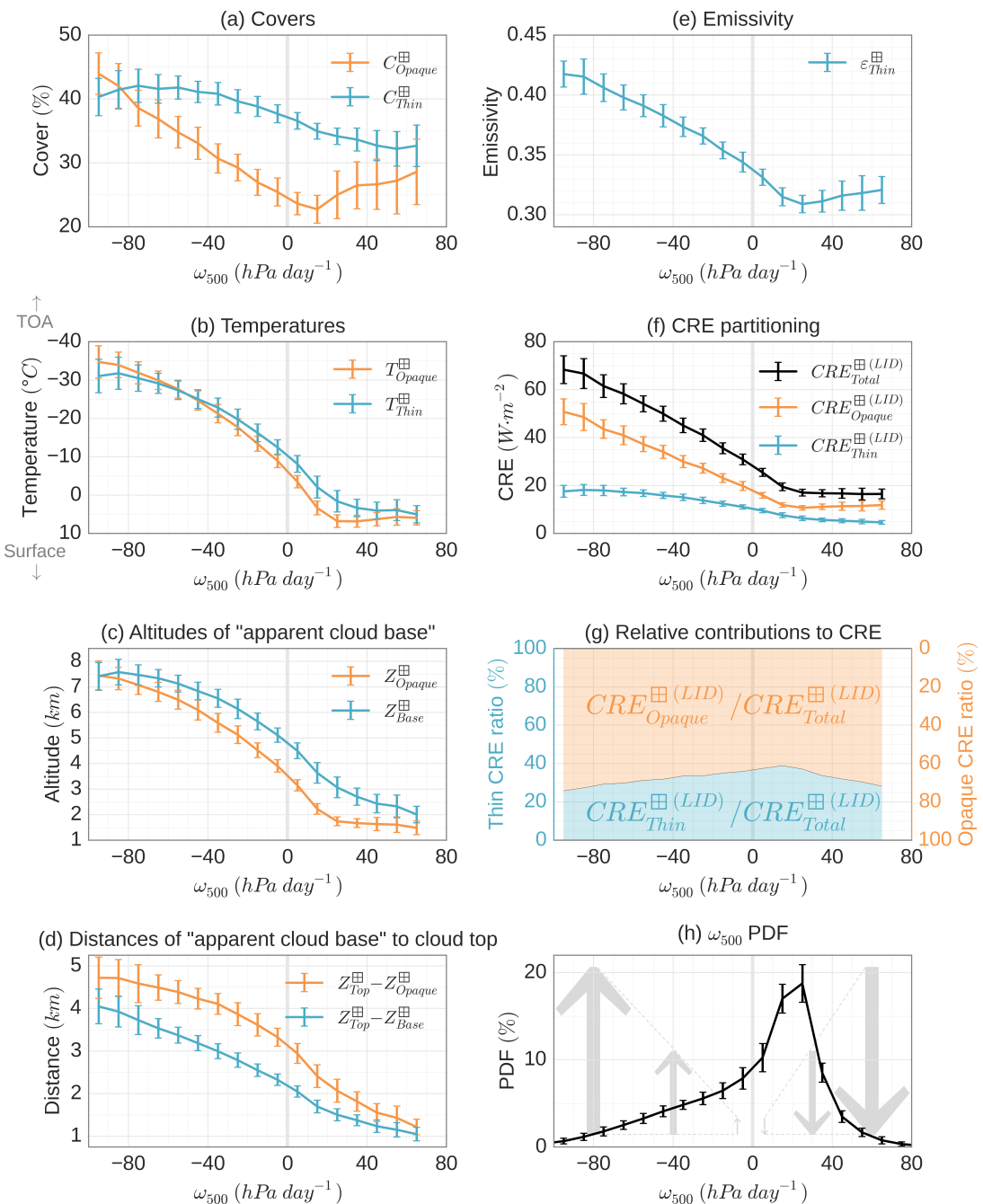

Figure 11. Tropical mean cloud properties and radiative effects as a function of the $500 \mathrm{hPa}$ pressure velocity: (a) $C_{\mathrm{opaque}}^{\boxplus}$ and $C_{\text {thin }}^{\boxplus}$, (b) $T_{\text {opaque }}^{\boxplus}$ among opaque clouds and $T_{\text {thin }}^{\boxplus}$ among thin clouds, (c) $Z_{\text {opaque }}^{\boxplus}$ among opaque clouds and $Z_{\text {base }}^{\boxplus}$ among thin clouds, (d) $Z_{\text {top }}^{\boxplus}-$ $Z_{\text {opaque }}^{\boxplus}$ among opaque clouds and $Z_{\text {top }}^{\boxplus}-Z_{\text {base }}^{\boxplus}$ among thin clouds, (e) $\varepsilon_{\text {thin }}^{\boxplus}$ among thin clouds, (f) total CRE, opaque CRE and thin CRE, and (g) relative contribution of opaque CRE and thin CRE. (h) Distribution of the $500 \mathrm{hPa}$ pressure velocity. Results obtained from monthly mean $2^{\circ} \times 2^{\circ}$ gridded variables. Only nighttime conditions over ice-free oceans for the $2008-2015$ period in $\left[30^{\circ} \mathrm{S}-30^{\circ} \mathrm{N}\right]$ are considered. The error bars show the \pm standard deviation of the 96-monthly means.

dynamical regime. Radiative cloud temperatures $T_{\mathrm{opaque}}^{\boxplus}$ and $T_{\text {thin }}^{\boxplus}$ presented in Fig. $11 \mathrm{~b}$ were built respectively from temperatures at altitudes $Z_{\text {opaque }}^{\dagger}$ and $Z_{\text {top }}^{\dagger}$, and from temperatures at altitudes $Z_{\text {base }}^{\mid}$and $Z_{\text {top }}^{\perp}$ (see Sect. 3.1). The linear decrease from 20 to $-100 \mathrm{hPa} \mathrm{day}^{-1}$ of $T_{\mathrm{opaque}}^{\boxplus}$ and $T_{\text {thin }}^{\boxplus}$ is due to the cumulative effects of a rising of the altitude of "apparent cloud base" ( $Z_{\text {opaque }}^{\mid}$for opaque clouds and $Z_{\text {base }}^{\mid}$for thin clouds; see monthly mean $2^{\circ} \times 2^{\circ}$ gridded $Z_{\text {opaque }}^{\boxplus}$ and $Z_{\text {thin }}^{\boxplus}$ on Fig. 11c) and an elongation of the cloud vertical distribution which gives even higher $Z_{\text {top }}^{\mid}$(see monthly mean $2^{\circ} \times 2^{\circ}$ gridded distance of apparent cloud base $Z_{\text {top }}^{\boxplus}-Z_{\text {opaque }}^{\boxplus}$ and $Z_{\text {top }}^{\boxplus}-Z_{\text {base }}^{\boxplus}$ on Fig. 11d). Figure 11e shows the distribution in dynamical regimes of $\varepsilon_{\text {thin }}$. It increases from 0.31 to 0.42 between 20 and $-100 \mathrm{hPa} \mathrm{day}^{-1}$, being almost invariant from month to month, and it is around 0.32 on average in subsidence.

An interesting point that appears in these figures is that, in the tropics, the very small variability in the relationship between cloud properties and $\omega_{500}$ in dynamical regimes between 20 and $-100 \mathrm{hPa} \mathrm{day}^{-1}$ : standard deviation is around $2.5 \%$ for $C_{\text {opaque }}^{\boxplus}$, less than $2 \%$ for $C_{\text {thin }}^{\boxplus}$, around $2.5 \mathrm{~K}$ for $T_{\text {opaque }}^{\boxplus}$, less than $3 \mathrm{~K}$ for $T_{\text {thin }}^{\boxplus}$, approximately 0.01 for $\varepsilon_{\text {thin }}$, around $350 \mathrm{~m}$ for $Z_{\text {opaque }}^{\boxplus}$ and $Z_{\text {base }}^{\boxplus}, 300 \mathrm{~m}$ for $Z_{\text {top }}^{\boxplus}-Z_{\text {opaque }}^{\boxplus}$ and $200 \mathrm{~m}$ for $Z_{\text {top }}^{\boxplus}-Z_{\text {base }}^{\boxplus}$. So, a change in the large-scale dynamic regimes produces a change in the cloud properties 
and CRE that seem predictable. For example, if $\omega_{500}$ on a region changes from -40 to $-80 \mathrm{hPaday}^{-1}, C_{\text {opaque }}^{\boxplus}$ will increase by $8 \%\left(C_{\text {thin }}^{\boxplus}\right.$ will remain more or less constant), $T_{\text {opaque }}^{\boxplus}$ will decrease by $10 \mathrm{~K}$ and $T_{\text {thin }}^{\boxplus}$ by $7 \mathrm{~K}$, and $\varepsilon_{\text {thin }}$ will increase by 0.03 . These cloud changes would increase the CRE by $17 \mathrm{~W} \mathrm{~m}^{-2}$, including $14 \mathrm{~W} \mathrm{~m}^{-2}$ from opaque clouds (Fig. 11f). Because $C_{\text {thin }}^{\boxplus}$ will remain more or less constant, whereas $C_{\mathrm{opaque}}^{\boxplus}$ will increase with a decrease of $\omega_{500}$ in ascendance, the relative contribution of opaque clouds to the total CRE will increase with convection. This is why we see in Fig. $11 \mathrm{~g}$ a decrease of the thin-cloud relative contribution from 20 to $-100 \mathrm{hPa}^{-1}{ }^{-1}$.

Because cloud properties seem to be invariant for dynamical regimes between 20 and $-100 \mathrm{hPaday}^{-1}$, a change in the tropics of the large-scale circulation should lead to a predictable change in the CRE in regions that stay in this range of dynamical regimes, linked to the spatial distribution (both covers and altitudes) of opaque clouds and thin clouds sounded by CALIOP. For example, general circulation models suggest that a warmer climate will see a narrowing of the ascending branch of the Hadley cell (e.g., Su et al., 2014), which means less convective regions and more subsiding regions. This should result in a predictable decrease of the CRE, knowing the changes of $\omega_{500}$ for some part of the tropics.

\section{Limitations of the OLR linear expression}

In this study, from the direct measurement of the altitude of opacity for a spaceborne lidar termed $Z_{\text {opaque }}^{\mid}$, we were able to infer the radiative temperature of opaque clouds $T_{\text {opaque, }}^{\mid}$ which we found linearly related to the OLR. We propose $Z_{\text {opaque as a good candidate for providing an observational }}^{\mid}$ constraint on the LW CRE and we tested the linear relationship on different scales from instantaneous to monthly means. In this section, we list possible sources of uncertainty.

\subsection{Cloud radiative temperatures $T_{\text {opaque }}^{\mid}$and $T_{\text {thin }}^{\mid}$}

The definitions of the cloud radiative temperatures $T_{\text {opaque }}^{\mid}$ and $T_{\text {thin }}^{\mid}$(Sect. 3.1) only take into account the apparent cloud edges seen by the lidar ( $Z_{\text {top }}^{\mid}$and $Z_{\text {opaque }}^{\mid}$or $Z_{\text {base }}^{\mid}$). A temperature defined by a centroid altitude (Garnier et al., 2012) would better account for the cloud vertical profile and could give a better estimate of the equivalent radiative temperature. However, our results show that the CRE is mainly driven by $Z_{\text {opaque }}^{\mid}$and $Z_{\text {top }}^{\mid}$above opaque clouds and $Z_{\text {base }}^{\mid}$ and $Z_{\text {top }}^{\mid}$above thin clouds. Furthermore, observation-based studies from the Atmospheric InfraRed Sounder (AIRS) and CALIOP showed that the radiative cloud height is located near the "apparent middle" of the cloud (Stubenrauch et al., 2010). The authors define the apparent middle of the cloud as the mid-point between the cloud top $\left(Z_{\text {top }}^{\mid}\right)$and the apparent cloud base seen by the CALIOP lidar ( $Z_{\text {base }}^{\mid}$for thin clouds and $Z_{\text {opaque }}$ for opaque clouds), consistently with our own definitions (Eqs. 1 and 2).

\subsection{Multilayer cloud and broken cloud situations}

Plotting the results of Fig. 6 in single-cloud-layer situations (Fig. E3c, d) gives better correlation coefficients, with $R=0.99$ for opaque clouds and $R=0.92$ for thin clouds. This shows that our linear expression does not capture nonlinearities which can occur in multilayer situations (Fig. E3e, f). As an example, all the occurrences far away above the identity line in Fig. 6a are due to multilayer situations. For single columns with opaque cloud, taking into account the optical depth of the thinner cloud which overlaps, an opaque cloud in the expression of $T_{\mathrm{opaque}}^{\mid}$improves the results for the multilayer scenario from $R=0.79$ (Fig. E3e) to $R=0.86$ (Fig. E4). However, this subtlety adds complexity to the computation of $T_{\text {opaque }}^{\mid}$, and provides small improvements to a simple expression which already provides very satisfying results when considering all scenarios $(R=0.95$ on Fig. 6a).

When clouds are broken, single lidar shots, having a $90 \mathrm{~m}$ diameter footprint, can fall onto the edge of an opaque cloud, leading to signals from both cloud and the atmosphere and surface below the cloud in the same lidar profile. In this case an opaque cloud can appear to be semi-transparent. Thus, the frequency of liquid clouds $\left(T>0{ }^{\circ} \mathrm{C}\right)$ classified as thin clouds (Fig. 4c) may be exaggerated, as most liquid clouds are optically dense and not penetrated by lidar. This misclassification does not affect the computation of OLR, as $\mathrm{OLR}_{\text {thin }}^{\odot}$ derived from lidar observations when $T_{\text {thin }}^{\ominus}>0{ }^{\circ} \mathrm{C}$ show excellent agreement with measurements made by CERES $(R=$ 0.94; Fig. E5).

\subsection{Evaluation of the OLR over thin clouds}

We saw that the theoretical linear expression of $\mathrm{OLR}_{\text {thin }}^{\mid}$for a fixed $\varepsilon_{\text {thin }}^{\mid}$overestimates the simulated relationship, by up to $+10 \mathrm{~W} \mathrm{~m}^{-2}$ in many cases (Sect. 4.1 ). This is partly due to the linear theoretical expression not taking into account the scattering of the LW radiation within the clouds. This may partially explain why $\mathrm{OLR}_{\text {thin }}^{\oslash \text { (LID) }}$ is larger than the measured OLR ${ }_{\text {thin }}^{\otimes \text { (CERES) }}$ (Fig. 6b). However, we do not think this should substantially affect the global-scale partitioning of $\mathrm{CRE}_{\text {total }}^{\boxplus(\mathrm{LID})}$ between $\mathrm{CRE}_{\text {opaque }}^{\boxplus(\mathrm{LID})}$ and $\mathrm{CRE}_{\text {thin }}^{\boxplus(\mathrm{LID})}$, because replacing $\mathrm{CRE}_{\text {thin }}^{\boxplus(\mathrm{LID})}$ with the difference $\mathrm{CRE}_{\text {total }}^{\boxplus(C E R E S)}-$ $\mathrm{CRE}_{\text {opaque }}^{\boxplus(\mathrm{LID})}$ only increases the contribution of opaque clouds to the total CRE to $74 \%$ instead of $73 \%$. Also, the value of $\varepsilon_{\text {thin }}^{\boxplus}$ used to construct $\operatorname{OLR}_{\text {thin }}^{\boxplus(\mathrm{LID})}$ does not account for thin-cloud single columns where no "clear" bin is found below the cloud (these clouds are not present in the $\varepsilon_{\text {thin }}^{\mid}$PDFs of Fig. 4d). This happens when very low clouds are present in the lowest $480 \mathrm{~m}$ bin, and so emissivities of thin clouds close to the surface are not taken into account in the aver- 
aged $\varepsilon_{\text {thin }}^{\boxplus}$. However, since all these "missed" cloud emissivities are from clouds near the surface, their temperature is certainly close to the surface temperature and their LW CRE should be small. So, this effect should have no significant impact on the presented results.

Further, applying $\mathrm{OLR}_{\text {thin }}^{\perp}$ Eq. (4) to $2^{\circ} \times 2^{\circ}$ gridded variables introduces errors, since the equation is nonlinear (the product of $T_{\text {thin }}^{\mid}$and $\varepsilon_{\text {thin }}^{\mid}$) unlike Eq. (5) for the $\operatorname{OLR}_{\text {opaque }}^{\mid}$,

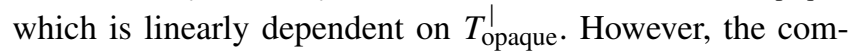
parison of the computed gridded OLR $\mathrm{total}^{\boxplus(\mathrm{LID})}$ against the measured OLR ${ }_{\text {total }}^{\boxplus(C E R E S)}$ has shown very good agreement.

Finally, since one of the objectives of the GOCCP product was to avoid false cloud detections during both nighttime and daytime conditions, the signal threshold chosen for cloud detection is quite large, meaning that high clouds with optical depths smaller than about 0.07 are absent from GOCCP (Chepfer et al., 2010, 2013). These subvisible cirrus clouds are therefore excluded from this study, but as their emissivities are very small (smaller than about 0.03 ), they would likely not impact our results.

\subsection{Gridded OLR}

Concerning gridded OLR, we used monthly mean $\mathrm{OLR}_{\text {clear }}^{\boxplus}$ from CERES-EBAF in Eqs. (4)-(5) instead of instantaneous $\mathrm{OLR}_{\text {clear }}^{\boxplus}$ from C3M since this product is only available up to April 2011. Clear-sky OLR from CERES-EBAF data is derived only from measurements over clear-sky atmospheric columns which are generally drier than the clear part of a cloudy atmospheric CERES column. Because a drier atmospheric column leads to a stronger OLR (e.g., Spencer and Braswell, 1997; Dessler et al., 2008; Roca et al., 2012), $\mathrm{OLR}_{\text {clear }}^{\boxplus}$ from CERES-EBAF should overestimate OLR $R_{\text {clear }}^{\boxplus}$ from $C 3 \mathrm{M}$ on average. The diurnal cycle, which is taken into account in $\mathrm{OLR}_{\text {clear }}^{\boxplus}$ from CERES-EBAF but not in $\mathrm{OLR}_{\text {clear }}^{\boxplus}$ from C3M (since we only used nighttime observations) could also play a role in the difference. We found an increase of $0.6 \mathrm{~W} \mathrm{~m}^{-2}$ for the global mean $\mathrm{OLR}_{\text {total }}^{\boxplus(\mathrm{LID})}$ computed with $\mathrm{OLR}_{\text {clear }}^{\boxplus}$ from CERES-EBAF compared to OLR $\mathrm{total}^{\boxplus(\mathrm{LID})}$ computed with $\mathrm{OLR}_{\mathrm{clear}}^{\boxplus}$ from C3M for the 2008-2010 period.

Differences between OLR $\mathrm{total}_{\text {t(LID) }}$ and OLR $\mathrm{T}_{\text {total }}^{\boxplus(\mathrm{CERES})}$ could also be related to multilayer clouds in atmospheric single columns, to cloud microphysical properties, and to differences in local atmospheric properties. However, using this very simple expression for the OLR gives an excellent correlation $(R=0.95)$ between monthly mean $\mathrm{OLR}_{\text {total }}^{\boxplus(\mathrm{LID})}$ and $\mathrm{OLR}_{\text {total }}^{\boxplus(\mathrm{CERES})}$ and a good agreement of the linear regression with the identity line (Appendix C, 2-D distribution of monthly means $2^{\circ} \times 2^{\circ}$ gridded measured and computed OLR is given in Fig. C1).

\subsection{Sensitivity to $Z_{\text {opaque }}^{\mid}$and to the multiple-scattering factor}

We also checked the sensitivity of $\mathrm{OLR}_{\text {total }}^{\boxplus(\mathrm{LI})}$ to the uncertainty in the altitude of full attenuation of the lidar signal. To do this, we conducted a test by moving $Z_{\text {opaque one bin }}^{\mid}$ up (480 m) in all opaque single columns (as moving $Z_{\text {opaque }}^{\mid}$ one bin down would have led to negative values for some $Z_{\text {opaque }}$ ). This changes the opaque-cloud radiative temperature, the $\mathrm{OLR}_{\text {opaque }}^{\mid(\text {(LID) }}$, and so the $\mathrm{OLR}_{\text {total }}^{\boxplus(\mathrm{LI})}$. Results show that after this change the global mean $\operatorname{OLR}_{\text {total }}^{\boxplus(\mathrm{LID})}$ is decreased by $0.9 \mathrm{~W} \mathrm{~m}^{-2}$ (Appendix D, Fig. D1a).

Finally, a fixed multiple-scattering factor $\eta$ is used for the retrieval of the thin-cloud emissivity, whereas there is evidence of a dependence on cloud temperature (Garnier et al., 2015). This could also play an important role in the differences between computed $\mathrm{OLR}_{\text {thin }}^{\ominus(\mathrm{LID})}$ and measured $\mathrm{OLR}_{\text {thin }}^{\oslash(\mathrm{CERES})}$. We tested the sensitivity of variability in $\eta$ on the computed $\mathrm{OLR}_{\text {total }}^{\boxplus(\mathrm{LID})}$ by modifying the value of $\eta$ from 0.6 to 0.5 . This reduced the global mean $\mathrm{OLR}_{\text {total }}^{\boxplus(\mathrm{LID})}$ by $1.1 \mathrm{~W} \mathrm{~m}^{-2}$ (Appendix D, Fig. D1b), which we consider negligible compared to the global mean value of $\mathrm{CRE}_{\text {total }}^{\boxplus(\mathrm{LID})}$ equal to $28.4 \mathrm{~W} \mathrm{~m}^{-2}$.

\section{Conclusion}

Simple radiative transfer models that estimate outgoing radiation at the TOA from a limited number of variables are useful for building a first-order decomposition of climate feedbacks. Such simple models exist in the SW domain but not in the LW domain, because LW fluxes are sensitive to the cloud vertical distribution, making the definition of such a simple model more challenging. In this work, we propose a simple LW radiative model which derives the LW CRE from five variables: two describing opaque clouds (opaque-cloud cover and opaque-cloud radiative temperature) and three which describe semi-transparent clouds (thin-cloud cover, thin-cloud radiative temperature, and thin-cloud emissivity).

The originality of our approach lies in how the cloud vertical distribution is described in this simple radiative transfer model. We have used three altitude levels which can be precisely measured by spaceborne lidar to describe the cloud vertical distribution within the simple radiative model. Our approach contrasts with techniques based on passive spaceborne sensors that retrieve effective cloud heights rather than profile information on the cloud vertical distribution. Our approach also contrasts with techniques based on full-profile lidar/radar measurements using 40 levels of altitude (or more) to describe cloud vertical distribution in the troposphere. In this work, we have taken advantage of the precision and accuracy of spaceborne lidar to describe cloud vertical structure but have retained only three levels of altitude to describe the cloud vertical distribution. Considering three levels of al- 
titude allows us build a simple radiative model, useful for first-order cloud feedback analysis, given that the more complex radiative transfer models using all altitude levels cannot be used for this purpose. We have selected the three levels of altitude that influence the OLR the most: (1) cloud-top altitude $Z_{\text {top }}^{\mid}$, (2) the level of full attenuation of the lidar laser beam $Z_{\text {opaque }}^{\mid}$in single columns containing an opaque cloud, and (3) cloud base $Z_{\text {base }}^{\mid}$in single columns containing semitransparent thin cloud. These three altitudes are first-order drivers of the LW CRE and have been measured precisely and unambiguously over a decade with the CALIPSO spaceborne lidar.

Using radiative transfer computations, we found that the OLR above an opaque cloud can be expressed linearly as a function of the "opaque temperature": OLR $\mathrm{OL}_{\text {opaue }}^{\mid(\mathrm{LID})}=$ $2.0 T_{\text {opaque }}^{\mid}-310$, where $T_{\text {opaque }}^{\mid}$is obtained from the combination of the cloud-top altitude $Z_{\text {top }}^{\mid}$, the level of full attenuation of the lidar laser beam $Z_{\text {opaque }}^{\mid}$, and a temperature profile taken from a reanalysis product. This simple relationship predicts that, if the altitude an opaque cloud increases so as to decrease its $T_{\text {opaque }}^{\mid}$by $1 \mathrm{~K}$, then the OLR is decreased by $2 \mathrm{~W} \mathrm{~m}^{-2}$. Using this linear relationship together with CALIPSO and CERES observations, we estimated that opaque clouds, which cover $35 \%$ of the ice-free ocean, contribute to $73 \%$ of the global mean CRE, whereas thin clouds, which cover $36 \%$, contribute to $27 \%$.

We checked the robustness of this linear relationship against observations at two different space- and timescales. Using instantaneous collocated observations from the CALIPSO lidar and CERES broadband radiometer data at the sensor spatial scale $(20 \mathrm{~km})$, we found a correlation coefficient of 0.95 between the lidar-derived $T_{\text {opaque }}^{\oslash}$ and the OLR measured by the broadband radiometer CERES. Averaging the same data monthly within $2^{\circ}$ latitude $\times 2^{\circ}$ longitude grid boxes, our derived OLR differs by $0.1 \mathrm{~W} \mathrm{~m}^{-2}$ from the OLR measured by CERES.
To conclude, this paper proposes a simple approximate solution to the complex problem of radiative transfer in the LW domain, which could be used to explore first-order LW cloud feedbacks in both observations and climate model simulations. On the observational side, future work will analyze the interannual variability of the record collected by spaceborne lidars and broadband radiometers: CALIPSO/CERES in the A-train (10+ years), followed by EarthCARE (Illingworth et al., 2014) to be launched in 2018. On the climate model simulation side, this new framework will be included in the Cloud Feedback Model Intercomparison Project (CFMIP) Observation Simulator Package (COSP; Bodas-Salcedo et al., 2011) lidar simulator (Chepfer et al., 2008) and applied to climate model outputs in order to quantify the contribution of each cloud property to the simulated cloud feedbacks.

Data availability. The GOCCP v3.0 products used in this article are available online through the GOCCP website at http://climserv. ipsl.polytechnique.fr/cfmip-obs/. CERES-EBAF data were obtained from the NASA Langley Research Center CERES ordering tool at http://ceres.larc.nasa.gov/. 


\section{Appendix A: Radiative cloud temperature}

Schematically, if we consider an optically uniform cloud, i.e., the LW optical depth $\tau^{\mathrm{LW} \mid}$ increases linearly through the cloud, with a cloud total LW optical depth $\tau_{\text {cloud }}^{\mathrm{LW}}$, we can compute the upward LW radiative flux emitted by the cloud at the top of the cloud $\left(\tau^{\mathrm{LW} \mid}=0\right)$. Neglecting the cloud particle reflectivity in the longwave domain, from the integral form of the Schwarzschild equation, we can express the upward zenithal spectral radiance $I_{v}^{\downarrow}$ emitted by the cloud at the top of the cloud:

$$
\begin{aligned}
& I_{v_{\text {cloud }}}^{\mid}\left(\tau^{\mathrm{LW} \mid}=0\right)=\int_{0}^{\tau_{\text {cloud }}^{\mathrm{LW} \mid}} B_{v}\left(T\left(\tau^{\mathrm{LW} \mid}\right)\right) e^{-\tau^{\mathrm{LW} \mid} \mathrm{d} \tau^{\mathrm{LW} \mid}} \\
& {\left[\mathrm{W} \mathrm{m}^{-2} \mathrm{sr}^{-1} \mathrm{~m}^{-1}\right] .}
\end{aligned}
$$

Considering a linear increase of the temperature with $\tau^{\mathrm{LW} \mid}$ from the cloud top to the cloud base $\left(T\left(\tau^{\mathrm{LW} \mid}\right)=k_{1} \tau^{\mathrm{LW} \mid}+\right.$ $k_{2}$ ) and integrating $I_{v_{\text {cloud }}}^{1}$ throughout the whole LW spectrum (using Stefan-Boltzmann law $\int B_{v} d v=\sigma T^{4} / \pi$ ), we can write the $\mathrm{LW}$ radiance $I^{\mathrm{LW} \mid}$ emitted by the cloud at the top of the cloud as

$$
\begin{aligned}
& I_{\text {cloud }}^{\mathrm{LW} \mid}\left(\tau^{\mathrm{LW} \mid}=0\right)=\int_{0}^{\tau_{\text {cloud }}^{\mathrm{LW}}} \frac{\sigma}{\pi}\left(k_{1} \tau^{\mathrm{LW} \mid}+k_{2}\right)^{4} e^{-\tau^{\mathrm{LW} \mid} \mathrm{d} \tau^{\mathrm{LW} \mid}} \\
& {\left[\mathrm{W} \mathrm{m}^{-2} \mathrm{sr}^{-1}\right] .}
\end{aligned}
$$

Assuming that the cloud emits as a Lambertian surface, the upward LW radiative flux $F^{\uparrow \mathrm{LW}}$ emitted by the cloud at the top of the cloud is given by

$$
\begin{gathered}
F_{\text {cloud }}^{\uparrow \mathrm{LW} \mid}\left(\tau^{\mathrm{LW} \mid}=0\right)=\int_{0}^{\tau_{\text {cloud }}^{\mathrm{LW}}} \sigma\left(k_{1} \tau^{\mathrm{LW} \mid}+k_{2}\right)^{4} e^{-\tau^{\mathrm{LW} \mid} \mathrm{d} \tau^{\mathrm{LW} \mid}} \\
{\left[\mathrm{W} \mathrm{m}^{-2}\right] .}
\end{gathered}
$$

Then, for specific values of coefficient $k_{1}$ and $k_{2}$, which determine the gradient of temperature in the cloud and the cloud-top temperature (and so the cloudbase temperature knowing $\tau_{\text {cloud }}^{\mathrm{LW}}$ ), it is possible to compute $F_{\text {cloud }}^{\uparrow \mathrm{LW} \mid}\left(\tau^{\mathrm{LW} \mid}=0\right)$ and then solve the equation $F_{\text {cloud }}^{\uparrow \mathrm{LW} \mid}\left(\tau^{\mathrm{LW} \mid}=0\right)=\varepsilon^{\mid} \sigma\left(T_{\text {rad }}^{\mid}\right)^{4}=\left(1-e^{-\tau_{\text {cloud }}^{\mathrm{LW} \mid}}\right) \sigma\left(T_{\text {rad }}^{\mid}\right)^{4}$ to find the corresponding equivalent cloud radiative temperature $T_{\text {rad }}^{\mid}$. 


\section{Appendix B: Vertical distributions of clouds directly observed by CALIOP}

For three regions, as for Fig. 4, Fig. B1 shows distributions of the distance between the cloud top and $Z_{\text {opaque }}^{\mid}$and the distance between the cloud top and cloud base. In the three regions, when an opaque cloud (Fig. B1a) is penetrated by the laser beam of the lidar, $Z_{\text {opaque }}^{\mid}$is mostly found in the first kilometer below $Z_{\text {top }}^{\dagger}$ (30\% in the tropical convective region, $52 \%$ in the midlatitudes region and $75 \%$ in the tropical subsiding region). The frequency distribution collapses after $1 \mathrm{~km}$ (note the logarithmic $y$ axis). The greater altitude differences between $Z_{\text {top }}^{\dagger}$ and $Z_{\text {opaque }}^{\uparrow}$ can be due to a more vertically spread cloud or to multiple cloud layers. If we look at the dashed lines, which represent the parts of the PDF considering only profiles without multiple layers, we can see that the curves of the three regions fall to zero around $4-5 \mathrm{~km}$. This means that all the parts of PDFs over $5 \mathrm{~km}$ are due to multilayer clouds.
Regarding thin clouds (Fig. B1b), we mostly found $Z_{\text {base }}$ in the first kilometer below $Z_{\text {top }}^{\downarrow}(49 \%$ in the tropical convective region, $68 \%$ in the midlatitudes region and $76 \%$ in the tropical subsiding region). The frequency distribution collapses after $1 \mathrm{~km}$ (again, note the logarithmic $y$ axis). The part of the PDF of profiles without multilayers (dashed lines), i.e., single columns which contain only one optically thincloud layer and so directly represent the geometrical thickness of thin clouds, fall to zero around $4-5 \mathrm{~km}$. This means, as for opaque clouds, that all the part of PDFs over $5 \mathrm{~km}$ are due to overlap of multilayer clouds. Furthermore, as PDFs collapse after $1 \mathrm{~km}$ in both Fig. B1a and b and for all regions, it suggests that the laser beam is completely attenuated almost every time when exceeding $1 \mathrm{~km}$ thickness.
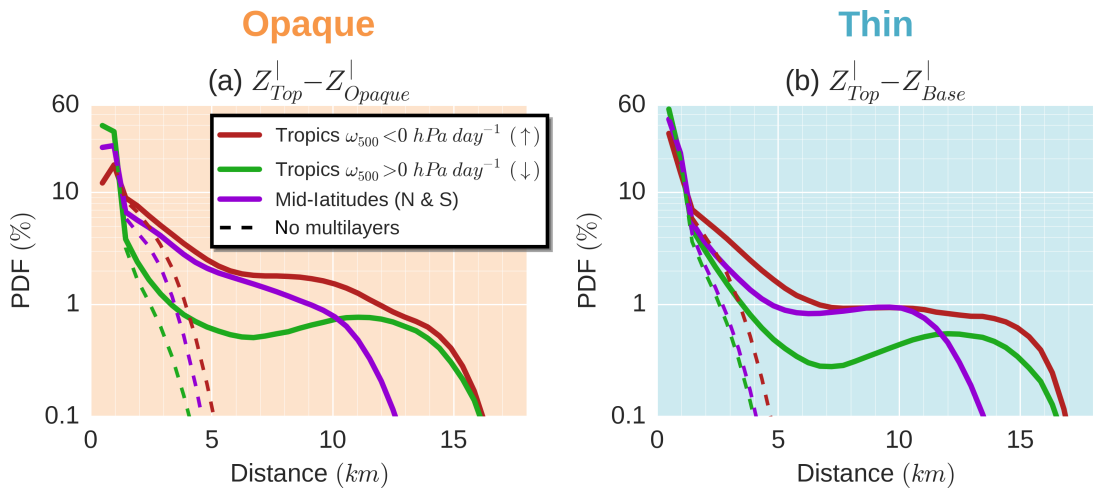

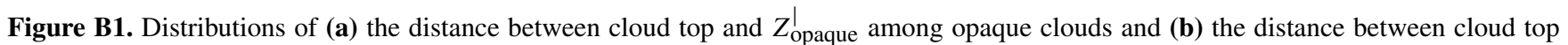
and cloud base among thin clouds in three regions: same as Fig. 4. Dashed lines represent the distribution only among single columns where a unique cloud layer was found (no multiple cloud layers). Only nighttime conditions over ice-free oceans for the 2008-2015 period are considered. 
Appendix C: Verification of the lidar-derived gridded OLR against CERES observations

Figure $\mathrm{C} 1$ shows the correlation between the OLR computed from lidar observations $\left(\mathrm{OLR}_{\text {total }}^{\boxplus(\mathrm{LID})}\right)$ and the OLR measured by the CERES radiometer on board the Aqua satellite on which we extract only footprints collocated with the CALIPSO ground track $\left(\mathrm{OLR}_{\mathrm{total}}^{\boxplus(\mathrm{CERES})}\right)$ for nighttime and over ice-free oceans on $2^{\circ} \times 2^{\circ}$ monthly means for the 2008 . We found an excellent correlation $(R=0.95)$ and the regression slope is near the one-to-one line, which reinforces our confidence in this simple OLR expression to correctly estimate the observed OLR.

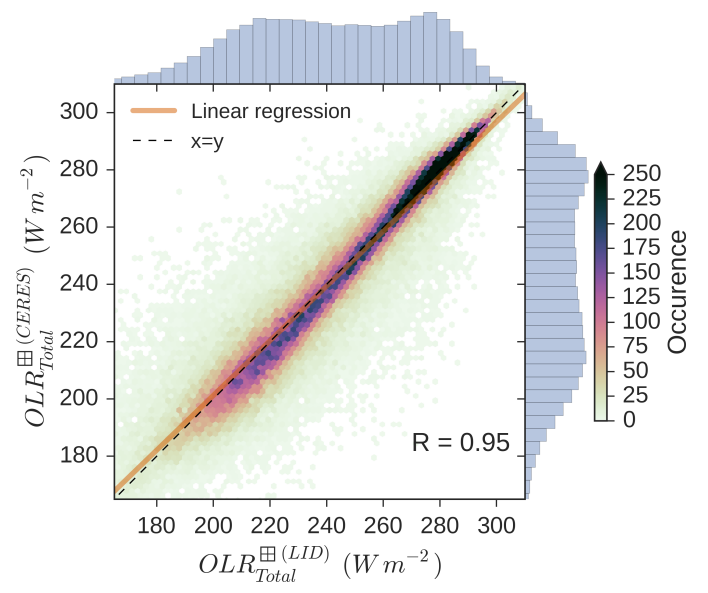

Figure C1. Comparison between observed and lidar-derived OLR on a monthly mean $2^{\circ} \times 2^{\circ}$ gridded scale. Only nighttime conditions over ice-free oceans for the year 2008 are considered. 


\section{Appendix D: Sensitivity of the lidar-derived gridded OLR to $Z_{\text {opaque }}^{\mid}$and to the multiple-scattering factor}

Figure D1a shows the difference between lidar-derived gridded OLR total $_{(\mathrm{LID})}$ shown in Fig. 7a and the one which would be

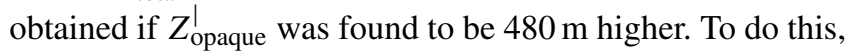
we replaced the altitude $Z_{\text {opaque }}^{\mid}$of each opaque-cloud single column found with the lidar by the bin above, so the altitude of $Z_{\text {opaque }}^{\mid}$is systematically increased by $480 \mathrm{~m}$. We then recomputed $\mathrm{OLR}_{\text {total }}^{\boxplus(\mathrm{LID})}$ in the exact same way as described in this paper. The effect of an increase in the altitude of $Z_{\text {opaque }}^{\mid}$ is a global mean decrease in $\mathrm{OLR}_{\text {total }}^{\boxplus(\mathrm{LID})}$ by $0.9 \mathrm{~W} \mathrm{~m}^{-2}$. Areas where $\mathrm{OLR}_{\text {total }}^{\boxplus(\mathrm{LID})}$ is the most affected correspond to areas with large values of opaque-cloud cover (patterns for 20082015 period on Fig. 2a are quite similar to those for the year 2008) except for the stratocumulus regions off the western coasts of the African, the American, and the Oceanic continents where $C_{\text {opaque }}^{\boxplus}$ is large but where the $\mathrm{OLR}_{\text {total }}^{\boxplus(\mathrm{LID})}$ change is not very pronounced. A higher $Z_{\text {opaque increases the level }}^{\mid}$ of the radiative temperature of the opaque clouds, so it decreases this temperature and then weakens $\mathrm{OLR}_{\text {total }}^{\boxplus(\mathrm{LID})}$. Since $\mathrm{OLR}_{\text {total }}^{\boxplus(\mathrm{LID})}$ is not affected as much in the stratocumulus regions, this suggests that vertical temperature gradient where these clouds are founded must be weak.

Figure D1b shows the difference between lidar-derived gridded OLR $\mathrm{R}_{\text {total }}^{\boxplus(\mathrm{LID})}$ shown in Fig. 7a and the one which is obtained using a fixed multiple-scattering factor $\eta=0.5$ instead of $\eta=0.6$. Decreasing $\eta$ increases the retrieved emissivity of the thin clouds by 0.05 . Consequently, regions that have many high thin clouds, thus having a strong cloud radiative effect, are regions where $\mathrm{OLR}_{\text {total }}^{\boxplus(\mathrm{LID})}$ is the most affected by this change (in the multiple-scattering factor), up to a decrease of $3.5 \mathrm{~W} \mathrm{~m}^{-2}$ in the Indonesian region.

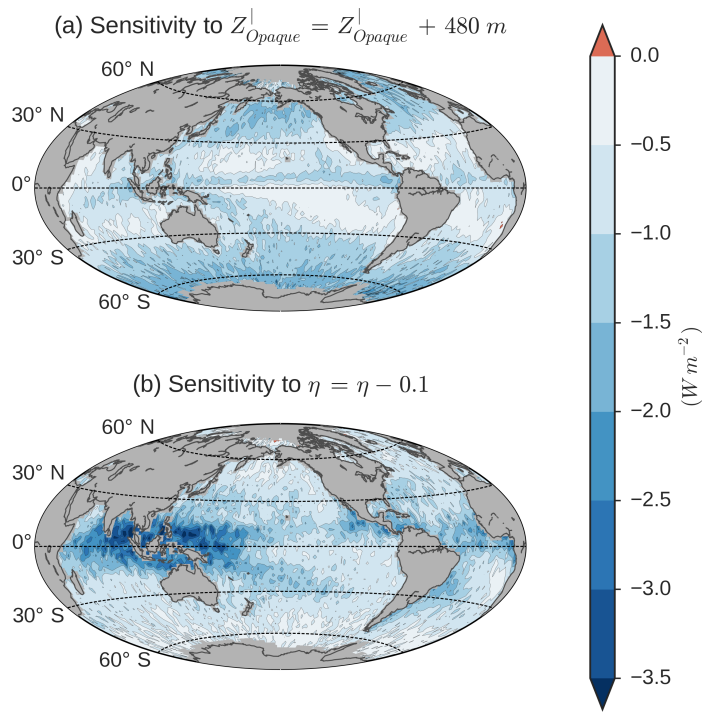

Figure D1. Sensitivity of the lidar-derived annual-mean gridded $\mathrm{OLR}_{\text {total }}^{\boxplus(\text { ID) }}$ to the altitude of full attenuation of the lidar into

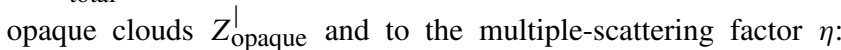
(a) difference between $\mathrm{OLR}_{\text {total }}^{\boxplus(\text { IID) }}$ of Fig. 7a and $\mathrm{OLR}_{\text {total }}^{\boxplus(\mathrm{LID})}$,

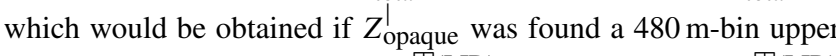
and (b) difference between OLR ${ }_{\text {total }}^{\boxplus \text { (LID) }}$ of Fig. 7a and $\mathrm{OLR}_{\text {total }}^{\boxplus(\mathrm{LID})}$ which is obtained using a fixed multiple-scattering factor $\eta=0.5$ instead of $\eta=0.6$. Only nighttime conditions over ice-free oceans for the year 2008 are considered. 


\section{Appendix E}

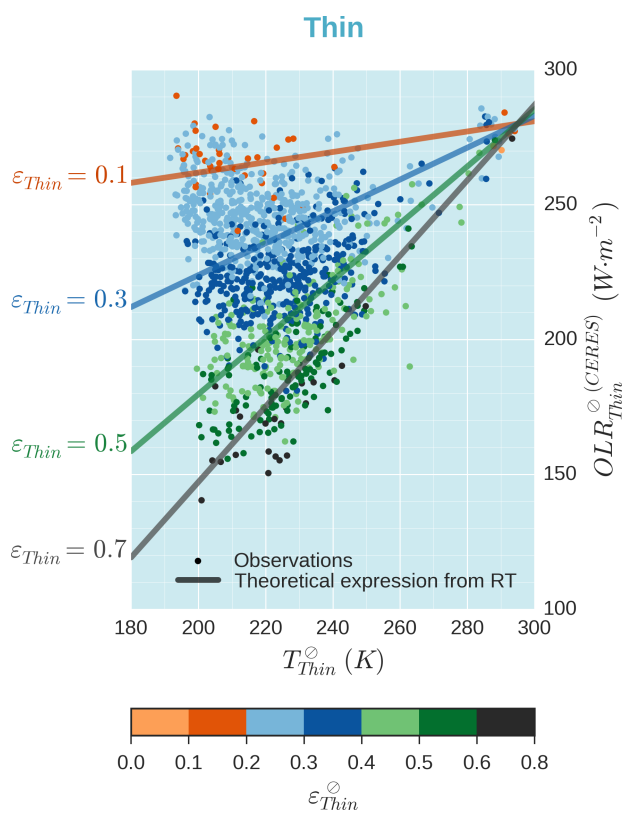

Figure E1. Comparison between observed and lidar-derived OLR, on a CERES footprint scale, as a function of $T_{\text {thin }}^{\oslash}$ and $\varepsilon_{\text {thin }}^{\oslash}$. Results obtained from CERES (dots) and CALIOP (lines) collocated measurements. Theoretical expressions are from Eq. (4). Same results as in Fig. $6 \mathrm{~b}$ but only for measurements where $\mathrm{OLR}_{\text {clear }}^{\oslash}$ is close to $280 \mathrm{~W} \mathrm{~m}^{-2}$ selected (OLR clear $^{\oslash}[275-285] \mathrm{W} \mathrm{m}^{-2}$ ), in order to only see the contribution of $T_{\text {thin }}^{\oslash}$ and $\varepsilon_{\text {thin }}^{\oslash}$ on the OLR. Only nighttime conditions over ice-free oceans for January 2008 are considered.
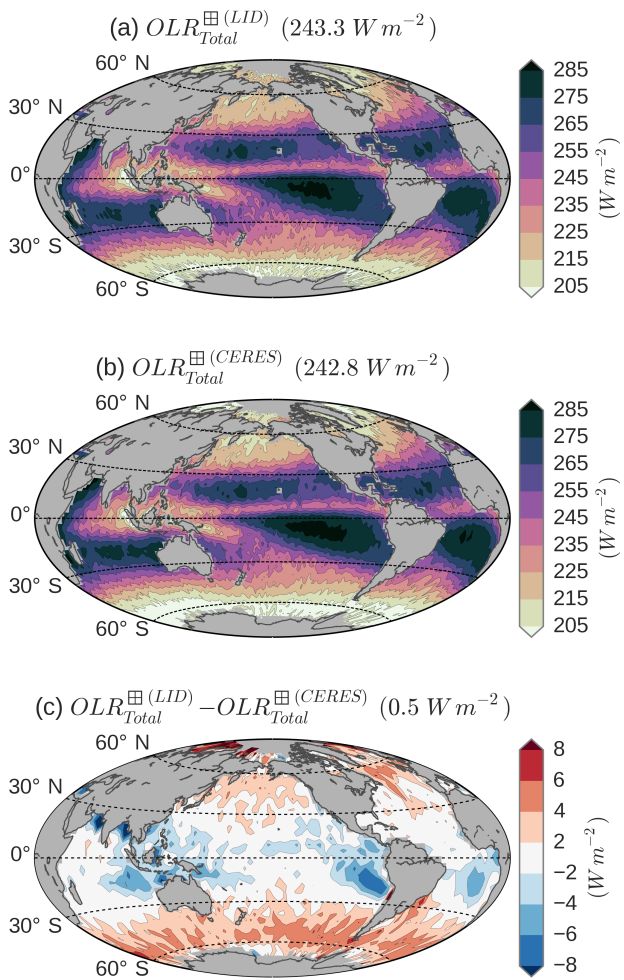

Figure E2. Same as Fig. 7 but using OLR ${ }_{\text {clear }}^{\boxplus}$ from CERES-EBAF instead of OLR ${ }_{\text {clear }}^{\boxplus}$ from CERES-Aqua in the calculation of OLR ${ }_{\text {total }}^{\boxplus(L I D)}$. 


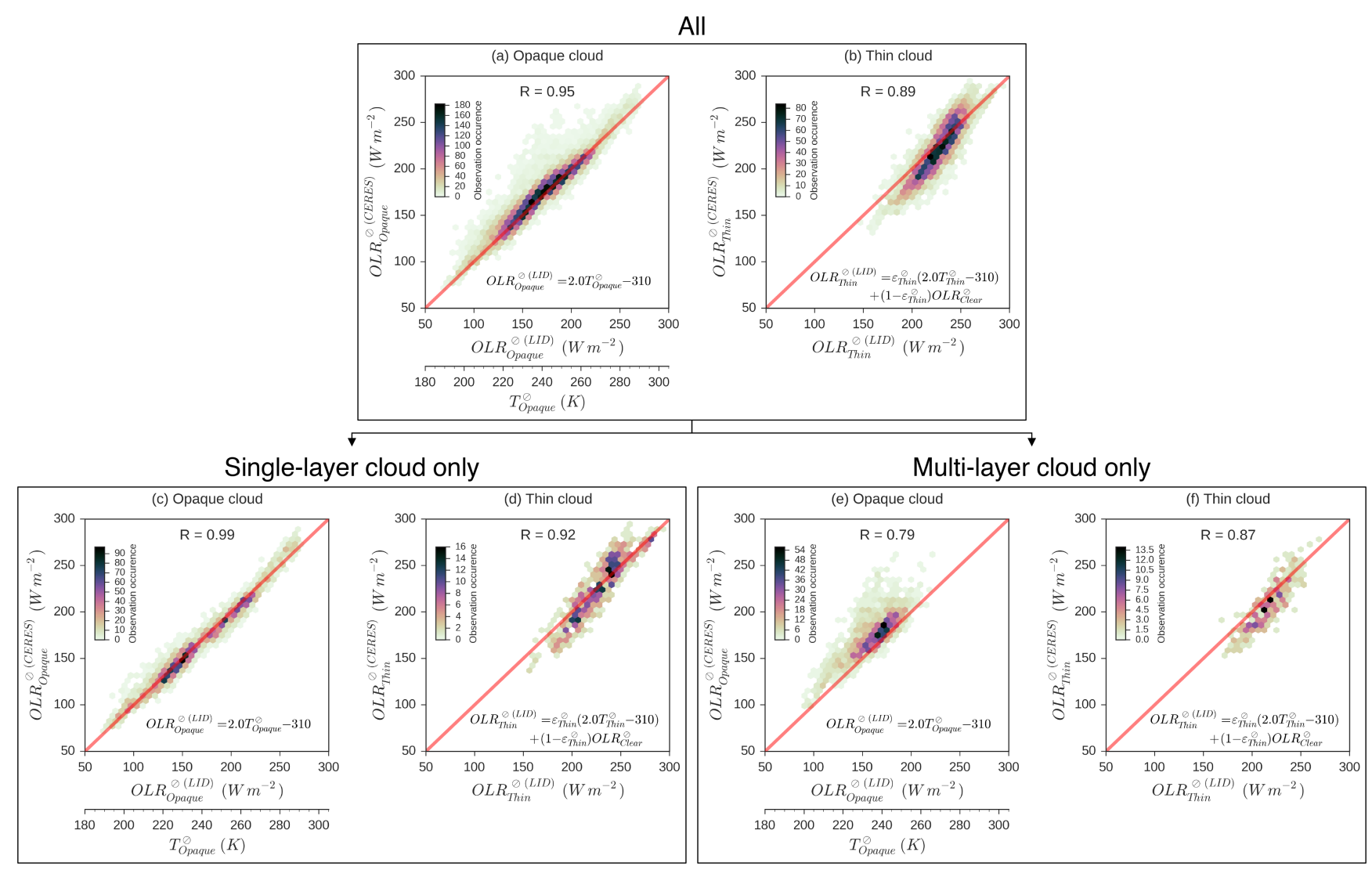

Figure E3. Panels $(\mathbf{a}, \mathbf{b})$ are the same as Fig. 6a and b. They are decomposed here into (c, d) single-layer cloud situations and (e, f) multilayer cloud situations.

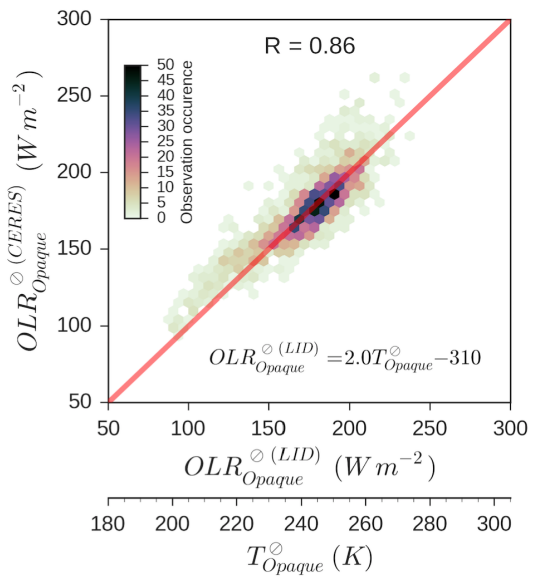

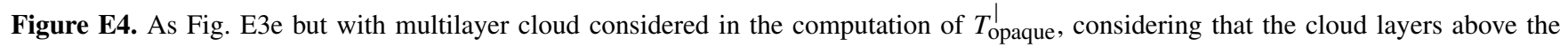
optically opaque cloud (below) have an equivalent emissivity $\varepsilon_{\text {above }}=0.3: T_{\text {opaque }}^{\dagger}=\left(1-\varepsilon_{\text {above }}\right) T_{\text {below }}^{\mid}+\varepsilon_{\text {above }} T_{\text {above }}^{\mid}$where $T_{\text {below }}^{\mid}=$

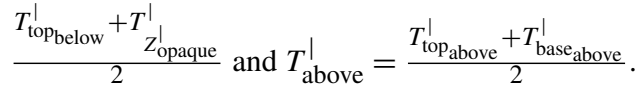




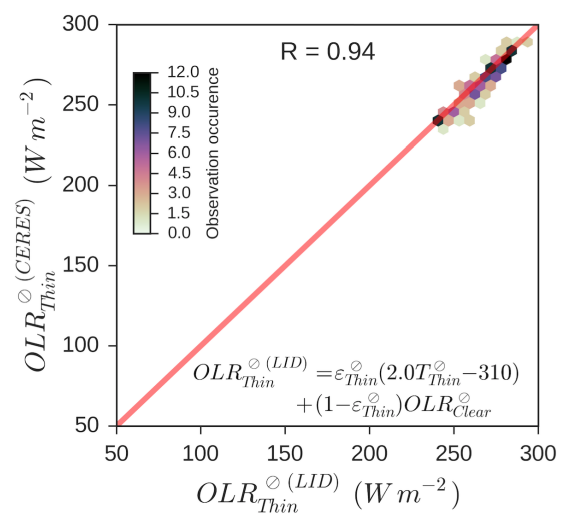

Figure E5. As Fig. $6 \mathrm{~b}$ but only with $T_{\text {thin }}^{\oslash}>0^{\circ} \mathrm{C}$, which could be liquid broken opaque clouds misclassified as thin clouds. 
Competing interests. The authors declare that they have no conflict of interest.

Acknowledgements. We would like to thank NASA/CNES for access to the CALIPSO level 1 data and the ClimServ center for the use of the computing cluster. We also thank CNES for supporting the development of CALIPSO-GOCCP. The authors are grateful to the three anonymous referees of this paper for helpful comments and suggestions.

Edited by: Andrew Sayer

Reviewed by: three anonymous referees

\section{References}

Bates, J. R.: Some considerations of the concept of climate feedback, Q. J. Roy. Meteor. Soc., 133, 545-560, https://doi.org/10.1002/qj.62, 2007.

Berrisford, P., Dee, D., Poli, P., Brugge, R., Fielding, K., Fuentes, M., Kallberg, P., Kobayashi, S., Uppala, S., and Simmons, A.: The ERA-Interim archive Version 2.0, ERA Report Series 1, ECMWF, Shinfield Park, Reading, UK, 2011.

Bodas-Salcedo, A., Webb, M. J., Bony, S., Chepfer, H., Dufresne, J. L., Klein, S. A., Zhang, Y., Marchand, R., Haynes, J. M., Pincus, R., and John, V. O.: COSP: Satellite simulation software for model assessment, B. Am. Meteorol. Soc., 92, 1023-1043, https://doi.org/10.1175/2011BAMS2856.1, 2011.

Bony, S., Colman, R., Kattsov, V. M., Allan, R. P., Bretherton, C. S., Dufresne, J.-L., Hall, A., Hallegatte, S., Holland, M. M., Ingram, W., Randall, D. A., Soden, B. J., Tselioudis, G., and Webb, M. J.: How Well Do We Understand and Evaluate Climate Change Feedback Processes?, J. Climate, 19, 3445-3482, https://doi.org/10.1175/JCLI3819.1, 2006.

Boucher, O., Randall, D., Artaxo, P., Bretherton, C., Feingold, G., Forster, P., Kerminen, V.-M., Kondo, Y., Liao, H., Lohmann, U., Rasch, P., Satheesh, S. K., Sherwood, S., Stevens, B., and Zhang, X. Y.: Clouds and aerosols, in: Climate Change 2013: The Physical Science Basis. Contribution of Working Group I to the Fifth Assessment Report of the Intergovernmental Panel on Climate Change, Cambridge University Press, UK and New York, USA, 571-657, https://doi.org/10.1017/CBO9781107415324.016, 2013.

Caldwell, P. M., Zelinka, M. D., Taylor, K. E., and Marvel, K.: Quantifying the Sources of Intermodel Spread in Equilibrium Climate Sensitivity, J. Climate, 29, 513-524, https://doi.org/10.1175/JCLI-D-15-0352.1, 2016.

Cesana, G. and Chepfer, H.: How well do climate models simulate cloud vertical structure? A comparison between CALIPSOGOCCP satellite observations and CMIP5 models, Geophys. Res. Lett., 39, L20803, https://doi.org/10.1029/2012GL053153, 2012.

Cesana, G. and Chepfer, H.: Evaluation of the cloud thermodynamic phase in a climate model using CALIPSO-GOCCP, J. Geophys. Res., 118, 7922-7937, https://doi.org/10.1002/jgrd.50376, 2013.

Cess, R. D.: Global climate change: an investigation of atmospheric feedback mechanisms, Tellus, 27, 193-198, https://doi.org/10.3402/tellusa.v27i3.9901, 1975.
Cess, R. D., Potter, G. L., Blanchet, J. P., Boer, G. J., Del Genio, A. D., Déqué, M., Dymnikov, V., Galin, V., Gates, W. L., Ghan, S. J., Kiehl, J. T., Lacis, A. A., Le Treut, H., Li, Z.X., Liang, X.-Z., McAvaney, B. J., Meleshko, V. P., Mitchell, J. F. B., Morcrette, J.-J., Randall, D. A., Rikus, L., Roeckner, E., Royer, J. F., Schlese, U., Sheinin, D. A., Slingo, A., Sokolov, A. P., Taylor, K. E., Washington, W. M., Wetherald, R. T., Yagai, I., and Zhang, M.-H.: Intercomparison and interpretation of climate feedback processes in 19 atmospheric general circulation models, J. Geophys. Res., 95, 16601-16615, https://doi.org/10.1029/JD095iD10p16601, 1990.

Cess, R. D., Zhang, M. H., Ingram, W. J., Potter, G. L., Alekseev, V., Barker, H. W., Cohen-Solal, E., Colman, R. A., Dazlich, D. A., Genio, A. D. D., Dix, M. R., Dymnikov, V., Esch, M., Fowler, L. D., Fraser, J. R., Galin, V., Gates, W. L., Hack, J. J., Kiehl, J. T., Le Treut, H., Lo, K. K.-W., McAvaney, B. J., Meleshko, V. P., Morcrette, J.-J., Randall, D. A., Roeckner, E., Royer, J.-F., Schlesinger, M. E., Sporyshev, P. V., Timbal, B., Volodin, E. M., Taylor, K. E., Wang, W., and Wetherald, R. T.: Cloud feedback in atmospheric general circulation models: An update, J. Geophys. Res., 101, 12791-12794, https://doi.org/10.1029/96JD00822, 1996.

Chepfer, H., Bony, S., Winker, D., Chiriaco, M., Dufresne, J.-L., and Sèze, G.: Use of CALIPSO lidar observations to evaluate the cloudiness simulated by a climate model, Geophys. Res. Lett., 35, L15704, https://doi.org/10.1029/2008GL034207, 2008.

Chepfer, H., Bony, S., Winker, D., Cesana, G., Dufresne, J. L., Minnis, P., Stubenrauch, C. J., and Zeng, S.: The GCM-Oriented CALIPSO Cloud Product (CALIPSO-GOCCP), J. Geophys. Res., 115, D00H16, https://doi.org/10.1029/2009JD012251, 2010.

Chepfer, H., Cesana, G., Winker, D., Getzewich, B., Vaughan, M., and Liu, Z.: Comparison of Two Different Cloud Climatologies Derived from CALIOP-Attenuated Backscattered Measurements (Level 1): The CALIPSO-ST and the CALIPSO-GOCCP, J. Atmos. Ocean. Tech., 30, 725-744, https://doi.org/10.1175/JTECH-D-12-00057.1, 2013.

Chepfer, H., Noel, V., Winker, D., and Chiriaco, M.: Where and when will we observe cloud changes due to climate warming?, Geophys. Res. Lett., 41, 8387-8395, https://doi.org/10.1002/2014GL061792, 2014.

Colman, R.: A comparison of climate feedbacks in general circulation models, Clim. Dynam., 20, 865-873, https://doi.org/10.1007/s00382-003-0310-z, 2003.

Dessler, A. E., Yang, P., Lee, J., Solbrig, J., Zhang, Z., and Minschwaner, K.: An analysis of the dependence of clear-sky top-of-atmosphere outgoing longwave radiation on atmospheric temperature and water vapor, J. Geophys. Res., 113, D17102, https://doi.org/10.1029/2008JD010137, 2008.

Di Michele, S., McNally, T., Bauer, P., and Genkova, I.: Quality Assessment of Cloud-Top Height Estimates From Satellite IR Radiances Using the CALIPSO Lidar, IEEE T. Geosci. Remote, 51, 2454-2464, https://doi.org/10.1109/TGRS.2012.2210721, 2013.

Dubuisson, P., Dessailly, D., Vesperini, M., and Frouin, R.: Water vapor retrieval over ocean using nearinfrared radiometry, J. Geophys. Res., 109, D19106, https://doi.org/10.1029/2004JD004516, 2004.

Dufresne, J.-L. and Bony, S.: An Assessment of the Primary Sources of Spread of Global Warming Estimates from Cou- 
pled Atmosphere-Ocean Models, J. Climate, 21, 5135-5144, https://doi.org/10.1175/2008JCLI2239.1, 2008.

Evan, A. T., Heidinger, A. K., and Vimont D. J.: Arguments against a physical long-term trend in global ISCCP cloud amounts, Geophys. Res. Lett., 34, L04701, https://doi.org/10.1029/2006GL028083, 2007.

Fu, Q. and Liou, K. N.: On the Correlated k-Distribution Method for Radiative Transfer in Nonhomogeneous Atmospheres, J. Atmos. Sci., 49, 2139-2156, https://doi.org/10.1175/15200469(1992)049<2139:OTCDMF>2.0.CO;2, 1992.

$\mathrm{Fu}, \mathrm{Q}$. and Liou, K. N.: Parameterization of the Radiative Properties of Cirrus Clouds, J. Atmos. Sci., $\quad 50, \quad 2008-2025, \quad$ https://doi.org/10.1175/15200469(1993)050<2008:POTRPO>2.0.CO;2, 1993.

Garnier, A., Pelon, J., Dubuisson, P., Faivre, M., Chomette, O., Pascal, N., and Kratz, D. P.: Retrieval of cloud properties using CALIPSO Imaging Infrared Radiometer. Part I: effective emissivity and optical depth, J. Appl. Meteorol. Clim., 51, 14071425, https://doi.org/10.1175/JAMC-D-11-0220.1, 2012.

Garnier, A., Pelon, J., Vaughan, M. A., Winker, D. M., Trepte, C. R., and Dubuisson, P.: Lidar multiple scattering factors inferred from CALIPSO lidar and IIR retrievals of semi-transparent cirrus cloud optical depths over oceans, Atmos. Meas. Tech., 8, 2759 2774, https://doi.org/10.5194/amt-8-2759-2015, 2015.

Guzman, R., Chepfer, H., Noel, V., Vaillant de Guélis, T., Kay, J. E., Raberanto, P., Cesana, G., Vaughan, M. A., and Winker, D. M.: Direct atmosphere opacity observations from CALIPSO provide new constraints on cloud-radiation interactions, J. Geophys. Res., 122, 1066-1085, https://doi.org/10.1002/2016JD025946, 2017

Hansen, J., Lacis, A., Rind, D., Russell, G., Stone, P., Fung, I., Ruedy, R., and Lerner, J.: Climate sensitivity: Analysis of feedback mechanisms, Climate processes and climate sensitivity, Geophysical Monograph Series, edited by: Hansen, J. E. and Takahashi, T., Vol. 29, Washington, D.C., 1984.

Hartmann, D. L. and Larson, K.: An important constraint on tropical cloud-climate feedback, Geophys. Res. Lett., 29, 12-1-12-4, https://doi.org/10.1029/2002GL015835, 2002.

Hartmann, D. L., Ockert-Bell, M. E., and Michelsen, M. L.: The Effect of Cloud Type on Earth's Energy Balance: Global Analysis, J. Climate, 5, 1281-1304, https://doi.org/10.1175/15200442(1992)005<1281:TEOCTO>2.0.CO;2, 1992.

Haynes, J. M., Marchand, R. T., Luo, Z., Bodas-Salcedo, A., and Stephens, G. L.: A multipurpose radar simulation package: QuickBeam, B. Am. Meteorol. Soc., 88, 1723-1727, https://doi.org/10.1175/BAMS-88-11-1723, 2007.

Henderson, D. S., L'Ecuyer, T., Stephens, G., Partain, P., and Sekiguchi, M.: A Multisensor Perspective on the Radiative Impacts of Clouds and Aerosols, J. Appl. Meteorol. Clim., 52, 853871, https://doi.org/10.1175/JAMC-D-12-025.1, 2013.

Holz, R. E., Ackerman, S. A., Nagle, F. W., Frey, R., Dutcher, S., Kuehn, R. E., Vaughan, M. A., and Baum, B.: Global Moderate Resolution Imaging Spectroradiometer (MODIS) cloud detection and height evaluation using CALIOP, J. Geophys. Res., 113, D00A19, https://doi.org/10.1029/2008JD009837, 2008.

Illingworth, A. J., Barker, H. W., Beljaars, A., Ceccaldi, M., Chepfer, H., Clerbaux, N., Cole, J., Delanoë, J., Domenech, C., Donovan, D. P., Fukuda, S., Hirakata, M., Hogan, R. J., Huenerbein, A., Kollias, P., Kubota, T., Nakajima, T., Naka- jima, T. Y., Nishizawa, T., Ohno, Y., Okamoto, H., Oki, R., Sato, K., Satoh, M., Shephard, M. W., Velázquez-Blázquez, A., Wandinger, U., Wehr, T., and van Zadelhoff, G.-J.: The EarthCARE Satellite: The Next Step Forward in Global Measurements of Clouds, Aerosols, Precipitation, and Radiation, B. Am. Meteorol. Soc., 96, 1311-1332, https://doi.org/10.1175/BAMS-D-1200227.1, 2014.

Kato, S., Rose, F. G., Sun-Mack, S., Miller, W. F., Chen, Y., Rutan, D. A., Stephens, G. L., Loeb, N. G., Minnis, P., Wielicki, B. A., Winker, D. M., Charlock, T. P., Stackhouse, P. W., Xu, K.M., and Collins, W. D.: Improvements of top-of-atmosphere and surface irradiance computations with CALIPSO-, CloudSat-, and MODIS-derived cloud and aerosol properties, J. Geophys. Res., 116, D19209, https://doi.org/10.1029/2011JD016050, 2011.

Kay, J. E., Hillman, B. R., Klein, S. A., Zhang, Y., Medeiros, B., Pincus, R., Gettelman, A., Eaton, B., Boyle, J., Marchand, R., and Ackerman, T. P.: Exposing Global Cloud Biases in the Community Atmosphere Model (CAM) Using Satellite Observations and Their Corresponding Instrument Simulators, J. Climate, 25, 5190-5207, https://doi.org/10.1175/JCLI-D-11-00469.1, 2012.

Kiehl, J. T.: On the observed near cancellation between longwave and shortwave cloud forcing in tropical regions, J. Climate, 7, 559-565, https://doi.org/10.1175/15200442(1994)007<0559:OTONCB>2.0.CO;2, 1994.

Klein, S. A. and Hall, A.: Emergent Constraints for Cloud Feedbacks, Curr. Clim. Change Rep., 1, 276-287, https://doi.org/10.1007/s40641-015-0027-1, 2015.

Klein, S. A. and Jakob, C.: Validation and sensitivities of frontal clouds simulated by the ECMWF model, Mon. Weather Rev., 127, 2514-2531, https://doi.org/10.1175/15200493(1999)127<2514:VASOFC>2.0.CO;2, 1999.

Klein, S. A., Zhang, Y., Zelinka, M. D., Pincus, R., Boyle, J., and Gleckler, P. J.: Are climate model simulations of clouds improving? An evaluation using the ISCCP simulator, J. Geophys. Res., 118, 1329-1342, https://doi.org/10.1002/jgrd.50141, 2013.

Le Treut, H., Li, Z. X., and Forichon, M.: Sensitivity of the LMD general circulation model to greenhouse forcing associated with two different cloud water parameterizations, J. Climate, 7, 1827-1841, https://doi.org/10.1175/15200442(1994)007<1827:SOTLGC>2.0.CO;2, 1994.

L'Ecuyer, T. S., Wood, N. B., Haladay, T., Stephens, G. L., and Stackhouse, P. W.: Impact of clouds on atmospheric heating based on the R04 CloudSat fluxes and heating rates data set, J. Geophys. Res., 113, D00A15, https://doi.org/10.1029/2008JD009951, 2008.

Loeb, N. G., Wielicki, B. A., Doelling, D. R., Smith, G. L., Keyes, D. F., Kato, S., Manalo-Smith, N., and Wong, T.: Toward optimal closure of the Earth's top-of-atmosphere radiation budget, J. Climate, 22, 748-766, https://doi.org/10.1175/2008JCLI2637.1, 2009.

Mace, G. G, Houser, S., Benson, S., Klein, S. A., and Min, Q.: Critical Evaluation of the ISCCP Simulator Using GroundBased Remote Sensing Data, J. Climate, 24, 1598-1612, https://doi.org/10.1175/2010JCLI3517.1, 2011.

Marchand, R. and Ackerman, T.: An analysis of cloud cover in multiscale modeling framework global climate model simulations using 4 and $1 \mathrm{~km}$ horizontal grids, J. Geophys. Res., 115, D16207, https://doi.org/10.1029/2009JD013423, 2010. 
Marvel, K., Zelinka, M., Klein, S. A., Bonfils, C., Caldwell, P., Doutriaux, C., Santer, B. D., and Taylor, K. E.: External Influences on Modeled and Observed Cloud Trends, J. Climate, 28, 48204840, https://doi.org/10.1175/JCLI-D-14-00734.1, 2015.

Nam, C., Bony, S., Dufresne, J.-L., and Chepfer, H.: The "too few, too bright" tropical low-cloud problem in CMIP5 models, Geophys. Res. Lett., 39, L21801, https://doi.org/10.1029/2012GL053421, 2012.

Norris, J. R. and Evan A. T.: Empirical Removal of Artifacts from the ISCCP and PATMOS-x Satellite Cloud Records, J. Atmos. Ocean. Tech., 32, 691-702, https://doi.org/10.1175/JTECH-D14-00058.1, 2015.

Norris, J. R., Allen, R. J., Evan, A. T., Zelinka, M. D., O'Dell, C. W., and Klein, S. A.: Evidence for climate change in the satellite cloud record, Nature, 536, 72-75, https://doi.org/10.1038/nature18273, 2016.

Ramanathan, V.: Interactions between Ice-Albedo, LapseRate and Cloud-Top Feedbacks: An Analysis of the Nonlinear Response of a GCM Climate Model, J. Atmos. Sci., 34, 1885-1897, https://doi.org/10.1175/15200469(1977)034<1885:IBIALR>2.0.CO;2, 1977.

Rieger, V. S., Dietmüller, S., and Ponater, M.: Can feedback analysis be used to uncover the physical origin of climate sensitivity and efficacy differences?, Clim. Dynam., 49, 2831-2844, https://doi.org/10.1007/s00382-016-3476-x, 2016.

Roca, R., Guzman, R., Lemond, J., Meijer, J., Picon, L., and Brogniez, H.: Tropical and extra-tropical influences on the distribution of free tropospheric humidity over the intertropical belt, Surv. Geophys., 33, 565-583, https://doi.org/10.1007/s10712011-9169-4, 2012.

Rose, F. G., Rutan, D. A., Charlock, T., Smith, G. L., and Kato, S.: An Algorithm for the Constraining of Radiative Transfer Calculations to CERES-Observed Broadband Top-ofAtmosphere Irradiance, J. Atmos. Ocean. Tech., 30, 1091-1106, https://doi.org/10.1175/JTECH-D-12-00058.1, 2013.

Schneider, S. H.: Cloudiness as a Global Climatic Feedback Mechanism: The Effects on the Radiation Balance and Surface Temperature of Variations in Cloudiness, J. Atmos. Sci., 29, 1413-1422, https://doi.org/10.1175/15200469(1972)029<1413:CAAGCF>2.0.CO;2, 1972.

Shea, Y. L., Wielicki, B. A., Sun-Mack, S., and Minnis, P.: Quantifying the Dependence of Satellite Cloud Retrievals on Instrument Uncertainty, J. Climate, 30, 6959-6976, https://doi.org/10.1175/JCLI-D-16-0429.1, 2017.

Sherwood, S. C., Chae, J.-H., Minnis, P., and McGill, M.: Underestimation of deep convective cloud tops by thermal imagery, Geophys. Res. Lett., 31, L11102, https://doi.org/10.1029/2004GL019699, 2004.

Sherwood, S. C., Bony, S., Boucher, O., Bretherton, C., Forster, P. M., Gregory, J. M., and Stevens, B.: Adjustments in the Forcing-Feedback Framework for Understanding Climate Change, B. Am. Meteorol. Soc., 96, 217-228, https://doi.org/10.1175/BAMS-D-13-00167.1, 2015.

Soden, B. J., Held, I. M., Colman, R., Shell, K. M., Kiehl, J. T., and Shields, C. A.: Quantifying Climate Feedbacks Using Radiative Kernels, J. Climate, 21, 3504-3520, https://doi.org/10.1175/2007JCLI2110.1, 2008.

Spencer, R. W. and Braswell, W. D.: How Dry is the Tropical Free Troposphere? Implications for Global Warming Theory, B. Am.
Meteorol. Soc., 78, 1097-1106, https://doi.org/10.1175/15200477(1997)078<1097:HDITTF>2.0.CO;2, 1997.

Stamnes, K., Tsay, S.-C., Wiscombe, W., and Jayaweera, K.: Numerically stable algorithm for discrete-ordinate-method radiative transfer in multiple scattering and emitting layered media, Appl. Optics, 27, 2502-2509, https://doi.org/10.1364/AO.27.002502, 1988.

Stephens, G. L., Vane, D. G., Boain, R. J., Mace, G. G., Sassen, K., Wang, Z., Illingworth, A. J., O'Connor, E. J., Rossow, W. B., Durden, S. L., Miller, S. D., Austin, R. T., Benedetti, A., and Mitrescu, C.: The CloudSat mission and the A-Train: A new dimension of space-based observations of clouds and precipitation, B. Am. Meteorol. Soc., 83, 1771-1790, https://doi.org/10.1175/BAMS-83-12-1771, 2002.

Stephens, G. L., Winker, D. M., Pelon, J., Trepte, C., Vane, D. G., Yuhas, C. L., L'Ecuyer, T. S., and Lebsock, M. D. CloudSat and CALIPSO within the A-Train: Ten years of actively observing the Earth system, B. Am. Meteorol. Soc., https://doi.org/10.1175/BAMS-D-16-0324.1, online first, 2017.

Stubenrauch, C. J., Cros, S., Guignard, A., and Lamquin, N.: A 6-year global cloud climatology from the Atmospheric InfraRed Sounder AIRS and a statistical analysis in synergy with CALIPSO and CloudSat, Atmos. Chem. Phys., 10, 7197-7214, https://doi.org/10.5194/acp-10-7197-2010, 2010.

Stubenrauch, C. J., Rossow, W. B., Kinne, S., Ackerman, S., Cesana, G., Chepfer, H., Di Girolamo, L., Getzewich, B., Guignard, A., Heidinger, A., Maddux, B. C., Menzel, W. P., Minnis, P., Pearl, C., Platnick, S., Poulsen, C., Riedi, J., Sun-Mack, S., Walther, A., Winker, D., Zeng, S., and Zhao, G.: Assessment of Global Cloud Datasets from Satellites: Project and Database Initiated by the GEWEX Radiation Panel, B. Am. Meteorol. Soc., 94, 1031-1049, https://doi.org/10.1175/BAMS-D12-00117.1, 2013.

Su, H., Jiang, J. H., Zhai, C., Shen, T. J., Neelin, J. D., Stephens, G. L., and Yung, Y. L.: Weakening and strengthening structures in the Hadley Circulation change under global warming and implications for cloud response and climate sensitivity, J. Geophys. Res., 119, 5787-5805, https://doi.org/10.1002/2014JD021642, 2014.

Suarez, M. J., Bloom, S., daSilva, A., Dee, D., Bosilovich, M., Chern, J.-D., Pawson, S., Schubert, S., Sienkiewicz, M., Stajner, I., Tan, W.-W., and Wu, M.-L.: Documentation and validation of the Goddard Earth Observing System (GEOS) data assimilation system, version 4, Tech. Rep. Series on Global Modeling and Data Assimilation, Vol. 26, NASA/TM-2005-104606, 181 pp., 2005.

Taylor, K. E., Crucifix, M., Braconnot, P., Hewitt, C. D., Doutriaux, C., Broccoli, A. J., Mitchell, J. F. B., and Webb, M. J.: Estimating Shortwave Radiative Forcing and Response in Climate Models, J. Climate, 20, 2530-2543, https://doi.org/10.1175/JCLI4143.1, 2007.

Vaughan, M. A., Powell, K. A., Winker, D. M., Hostetler, C. A., Kuehn, R. E., Hunt, W. H., Getzewich, B. J., Young, S. A., Liu, Z., and McGill, M. J.: Fully Automated Detection of Cloud and Aerosol Layers in the CALIPSO Lidar Measurements, J. Atmos. Ocean. Tech., 26, 2034-2050, https://doi.org/10.1175/2009JTECHA1228.1, 2009.

Vial, J., Dufresne, J.-L., and Bony, S.: On the interpretation of intermodel spread in CMIP5 climate sensitivity estimates, Clim. Dy- 
nam., 41, 3339-3362, https://doi.org/10.1007/s00382-013-17259, 2013.

Wang, P.-H., Minnis, P., Wielicki, B. A., Wong, T., and Vann, L. B.: Satellite observations of long-term changes in tropical cloud and outgoing longwave radiation from 1985 to 1998, Geophys. Res. Lett., 29, 37-1-37-4, https://doi.org/10.1029/2001GL014264, 2002.

Watterson, I. G., Dix, M. R., and Colman, R. A.: A comparison of present and doubled $\mathrm{CO}_{2}$ climates and feedbacks simulated by three general circulation models, J. Geophys. Res., 104, 19431956, https://doi.org/10.1029/1998JD200049, 1999.

Webb, M. J., Lambert, F. H., and Gregory, J. M.: Origins of differences in climate sensitivity, forcing and feedback in climate models, Clim. Dynam., 40, 677-707, https://doi.org/10.1007/s00382012-1336-x, 2013.

Wetherald, R. T. and Manabe, S.: Cloud Feedback Processes in a General Circulation Model, J. Atmos. Sci., 45, 1397-1416, https://doi.org/10.1175/15200469(1988)045<1397:CFPIAG>2.0.CO;2, 1988.

Wielicki, B. A., Young, D. F., Mlynczak, M. G., Thome, K. J., Leroy, S., Corliss, J., Anderson, J. G., Ao, C. O., Bantges, R., Best, F., Bowman, K., Brindley, H., Butler, J. J., Collins, W., Dykema, J. A., Doelling, D. R., Feldman, D. R., Fox, N., Huang, X., Holz, R., Huang, Y., Jin, Z., Jennings, D., Johnson, D. G., Jucks, K., Kato, S., Kirk-Davidoff, D. B., Knuteson, R., Kopp, G., Kratz, D. P., Liu, X., Lukashin, C., Mannucci, A. J., Phojanamongkolkij, N., Pilewskie, P., Ramaswamy, V., Revercomb, H., Rice, J., Roberts, Y., Roithmayr, C. M., Rose, F., Sandford, S., Shirley, E. L., Smith, W. L., Soden, B., Speth, P. W., Sun, W., Taylor, P. C., Tobin, D., and Xiong, X.: Achieving Climate Change Absolute Accuracy in Orbit, B. Am. Meteorol. Soc., 94, 1519-1539, https://doi.org/10.1175/BAMS-D-1200149.1, 2013.

Williams, K. D. and Webb, M. J.: A quantitative performance assessment of cloud regimes in climate models, Clim. Dynam., 33, 141-157, https://doi.org/10.1007/s00382-008-0443-1, 2009.

Winker, D. M., Pelon, J., Coakley Jr, J. A., Ackerman, S. A., Charlson, R. J., Colarco, P. R., Flamant, P., Fu, Q., Hoff, R. M., Kittaka, C., Kubar, T. L., Le Treut, H., McCormick, M. P., Mégie, G., Poole, L., Powell, K., Trepte, C., Vaughan, M. A., and Wielicki, B. A.: The CALIPSO Mission: A Global 3D View of Aerosols and Clouds, Bull. Am. Meteorol. Soc., 91, 1211-1229, https://doi.org/10.1175/2010BAMS3009.1, 2010.

Yokohata, T., Emori, S., Nozawa, T., Tsushima, Y., Ogura, T., and Kimoto, M.: A simple scheme for climate feedback analysis, Geophys. Res. Lett., 32, L19703, https://doi.org/10.1029/2005GL023673, 2005.
Yue, Q., Kahn, B. H., Fetzer, E. J., Wong, S., Frey, R., and Meyer, K. G.: On the response of MODIS cloud coverage to global mean surface air temperature, J. Geophys. Res., 122, 966-979, https://doi.org/10.1002/2016JD025174, 2017.

Zelinka, M. D. and Hartmann, D. L.: The observed sensitivity of high clouds to mean surface temperature anomalies in the tropics, J. Geophys. Res., 116, D23103, https://doi.org/10.1029/2011JD016459, 2011.

Zelinka, M. D., Klein, S. A., and Hartmann, D. L.: Computing and Partitioning Cloud Feedbacks Using Cloud Property Histograms. Part I: Cloud Radiative Kernels, J. Climate, 25, 37153735, https://doi.org/10.1175/JCLI-D-11-00248.1, 2012a.

Zelinka, M. D., Klein, S. A., and Hartmann, D. L.: Computing and partitioning cloud feedbacks using cloud property histograms. Part II: Attribution to changes in cloud amount, altitude, and optical depth, J. Climate, 25, 3736-3754, 2012b.

Zelinka, M. D., Klein, S. A., Taylor, K. E., Andrews, T., Webb, M. J., Gregory, J. M., and Forster, P. M.: Contributions of Different Cloud Types to Feedbacks and Rapid Adjustments in CMIP5, J. Climate, 26, 5007-5027, https://doi.org/10.1175/JCLI-D-12$00555.1,2013$.

Zelinka, M. D., Zhou, C., and Klein, S. A.: Insights from a refined decomposition of cloud feedbacks, Geophys. Res. Lett., 43, 9259-9269, https://doi.org/10.1002/2016GL069917, 2016.

Zhang, M. H., Lin, W. Y., Klein, S. A., Bacmeister, J. T., Bony, S., Cederwall, R. T., Del Genio, A. D., Hack, J. J., Loeb, N. G., Lohmann, U., Minnis, P., Musat, I., Pincus, R., Stier, P., Suarez, M. J., Webb, M. J., Wu, J. B., Xie, S. C., Yao, M.-S., and Zhang, J. H.: Comparing clouds and their seasonal variations in 10 atmospheric general circulation models with satellite measurements, J. Geophys. Res., 110, D15S02, https://doi.org/10.1029/2004JD005021, 2005.

Zhang, Y., Rossow, W. B., Lacis, A. A., Oinas, V., and Mishchenko, M. I.: Calculation of radiative fluxes from the surface to top of atmosphere based on ISCCP and other global data sets: Refinements of the radiative transfer model and the input data, J. Geophys. Res., 109, D19105, https://doi.org/10.1029/2003JD004457, 2004.

Zhou, C., Zelinka, M. D., Dessler, A. E., and Yang P.: An Analysis of the Short-Term Cloud Feedback Using MODIS Data, J. Climate, 26, 4803-4815, https://doi.org/10.1175/JCLI-D-1200547.1, 2013. 